\title{
Predicting and capitalizing on stock market bears in the U.S.
}

Citation for published version (APA):

Straetmans, S. T. M., Candelon, B., \& Ahmed, J. (2012). Predicting and capitalizing on stock market bears in the U.S. METEOR, Maastricht University School of Business and Economics. METEOR Research Memorandum No. 019 https://doi.org/10.26481/umamet.2012019

Document status and date:

Published: 01/01/2012

DOI:

10.26481/umamet.2012019

Document Version:

Publisher's PDF, also known as Version of record

\section{Please check the document version of this publication:}

- A submitted manuscript is the version of the article upon submission and before peer-review. There can be important differences between the submitted version and the official published version of record.

People interested in the research are advised to contact the author for the final version of the publication, or visit the DOI to the publisher's website.

- The final author version and the galley proof are versions of the publication after peer review.

- The final published version features the final layout of the paper including the volume, issue and page numbers.

Link to publication

\footnotetext{
General rights rights.

- You may freely distribute the URL identifying the publication in the public portal. please follow below link for the End User Agreement:

www.umlib.nl/taverne-license

Take down policy

If you believe that this document breaches copyright please contact us at:

repository@maastrichtuniversity.nl

providing details and we will investigate your claim.
}

Copyright and moral rights for the publications made accessible in the public portal are retained by the authors and/or other copyright owners and it is a condition of accessing publications that users recognise and abide by the legal requirements associated with these

- Users may download and print one copy of any publication from the public portal for the purpose of private study or research.

- You may not further distribute the material or use it for any profit-making activity or commercial gain

If the publication is distributed under the terms of Article $25 \mathrm{fa}$ of the Dutch Copyright Act, indicated by the "Taverne" license above, 


\section{Maastricht University}

Bertrand Candelon, Jameel Ahmed, Stefan Straetmans

Predicting and Capitalizing on Stock Market Bears in the U.S.

$\mathrm{RM} / 12 / 019$

\section{METEOR}

Maastricht University School of Business and Economics

Maastricht Research school of Economics

of Technology and Organization

PO. Box 616

NL-6200 MD Maastricht

The Netherlands 


\title{
Predicting and Capitalizing on Stock Market Bears in the U.S.
}

\author{
Bertrand Candelon* Jameel Ahmed ${ }^{\dagger} \quad$ Stefan Straetmans ${ }^{\ddagger}$
}

April 18, 2012

ABSTRACT

$\mathbf{T}$ his paper attempts to predict the bear conditions on the US stock market. To this aim we elaborate simple predictive regressions, static and dynamic binary choice (BCM) as well as Markov-switching models. The in- and out-of-sample prediction ability is evaluated and we compare the forecasting performance of various specifications across as well as within models. It turns out that various dynamic extensions of static versions of probit and logit models reveal additional predictive information for both in- and out-of-sample fit. We also find that binary models outperform the Markov-switching model. With respect to the macro-financial variables, terms spreads, inflation and money supply turn out to be useful predictors. The results lead to useful implications for investors practicing active portfolio and risk management and for policy makers as tools to get early warning signals.

Keywords: Bear stock market, S\&P 500 Index, Macro-financial variables, Dynamic Binary Response models, Markov-switching model, Bry-Boschan algorithm, Active Trading Strategies.

JEL Classification: C22, C25, C53, G11 and G17.

\footnotetext{
${ }^{*}$ b.candelon@maastrichtuniversity.nl, School of Business and Economics, Department of Economics, Maastricht University, Maastricht, The Netherlands.

$\dagger$ J.Ahmed@maastrichtuniversity.nl, School of Business and Economics, Maastricht University, Maastricht, The Netherlands and State Bank of Pakistan, Karachi, Pakistan. This author gratefully acknowledges research support from Higher Education Commission of Pakistan. The usual disclaimer applies.

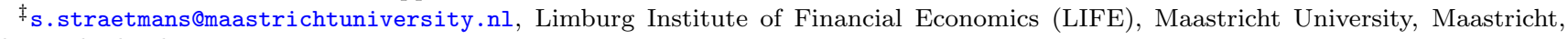
The Netherlands.
} 


\section{Introduction}

Forecasting stock market movements constitutes the dream for any investor and has policy implications as well. This quest of the holy grail by investors, and policy makers' interest in it, requires one to first determine the factors that are at the origin of these fluctuations. For return predictability, various macro-economic factors which presage the economic conditions have been proposed. For example, interest rate, inflation, default premium, aggregate output, money stocks, unemployment rate, consumption level, etc. are but a few them (see, e.g., Pesaran and Timmermann (1995); Rapach et al. (2005); Chen (2009) and references therein). Other financial variables like size and value factors, accounting ratios, sales growth, etc. have also been proposed (Cochrane (2008a) and references therein). However whereas some, for example Rapach et al. (2005) and Cochrane (2008b), find support for return predictability, the others, e.g., Goyal and Welch $(2003,2008)$ and Chen (2009), do not. A related strand of literature focuses on predicting the direction of the stock returns as it exhibits a larger degree of dependence over time, see e.g., Pesaran and Timmermann (1994); Christoffersen and Diebold (2006); Anatolyev and Gospordinov (2010); Nyberg (2011).

This paper however does not propose to predict the stock market returns nor the direction thereof but rather the periods of price decrease (bears) and increase (bulls) on the stock market. This forecasting exercise presents a major interest to both investors and policy makers. Prices during bear periods are generally depressed while there is an upsurge during the bulls. An ages old golden rule on stock market is: buy low, sell high. In this spirit, by forecasting the bear or bull periods, investors can exploit profitable opportunities by optimally timing their portfolios. Or, as Candelon et al. (2008) put it, duration of stock market cycle is the natural time horizon for "single-cycle" or "short-term" investor. For "multi-cycle" or "long-term" investor, this contains useful information for portfolio rebalancing. Moreover, active portfolio managers can utilize this information for placing directional bets. Shen (2003) find that at times when share prices deviate from fundamentals, timing of the portfolio re-balancing can accrue returns in excess of the benchmark portfolio, even after accounting for transaction costs. Resnick and Shoesmith (2002) also find that using home country yield spread, investors can find profitable market timing opportunities.

From policy perspective, the changes on stock market have also been said to precede the changes in business cycles ( Lamdin (2003)). Borio and Lowe (2002) have therefore advocated a policy response to contain asset price imbalances to maintain financial stability. Particularly, as noted by Candelon et al. (2008), bullish market induces large amounts of loan collateral - especially in poor regulatory environment- which increases the demand and goods price inflation. Therefore, a shift from bullish to bearish trend can cause widespread liquidity problems leading to credit crunch in financial markets. The central bank, which is also entrusted with the task of maintaining and ensuring financial stability, can use knowledge about such fluctuations on the stock market as an Early Warning Signal $(E W S)$. From fiscal policy perspective, for example, taxing capital gains provides revenue for the government. The knowledge of state of the stock market would therefore incite government to lower tax rate on capital gains in order to boost domestic as well foreign portfolio investment, hence stimulating the economic growth as well as its revenues.

In this paper, therefore, we focus on the prediction of bulls and bears on the United States stock market. Specifically, we consider forecasting bears on the stock market given its import for investors and policy makers. In order to extract these stock market cycles we use both parametric as well as non-parametric approaches. In the parametric approach, we extract filtered probabilities of bear states via a two-state Markov-switching model (MSM) using the changes in $(\log )$ aggregate stock market price index, S\&P 500. Non-parametrically, we subject the same market index to Bry and Boschan (1971) (BB) algorithm and obtain an indicator series showing periods of bulls and bears. We then venture to explain the filtered probabilities via linear predictive regressions and the indicator series via non-linear binary choice models $(\mathrm{BCM})$, using various macro-financial series as explanatory variables. Incidentally, we apply both the static as well as dynamic versions of BCM. In particular, we employ the dynamic versions of BCM proposed in Kauppi and Saikkonen (2008). 
Our work closely resembles to that of Chen (2009). However, we deviate in a number of ways. First, unlike Chen (2009), our focus is the dynamic rather than static version of the BCM as it adequately captures the stylized facts of the stock market cycles, i.e., the persistence and asymmetries. This is the first attempt, as far as we know, of predicting the monthly bear market states with macro-financial variables using Dynamic Autoregressive Binary Choice models of Kauppi and Saikkonen (2008). Second, not only the probit, as in Chen (2009), we also forecast bear conditions via the (dynamic) logit as well as Markov-switching models, augmented with macro-financial variables as exogenous. We are thus able to compare the forecasting performance not only across the linear (predictive regressions) and non-linear (BCM and MSM) models but also between the three most widely used models within the non-linear category (i.e., Probit, Logit and MSM). Besides using an eclectic battery of forecast evaluation metrics, we also compare this forecast performance of different nested and non-nested models via tests proposed in Clark and West (2007) and Diebold and Mariano (1995), respectively. Third, the sample period is extended to contain the recent global stock market downturn caused by the crisis in subprime mortgage sector in the United States. Fourth, we demonstrate the economic significance of our exercise by forming various active trading strategies on the stock market.

Our results show that various extensions of simple probit and logit models which introduce the dynamics are a useful value addition in terms of both in- and out-of-sample fit. Formal tests of equal predictive ability of such nested models via the Clark and West (2007) show that all the macro-financial variables reveal predictive content, albeit at varied horizons, when accounted for persistence and asymmetries. This is in contrast to the linear, static probit or logit and Markov-switching models where few variables are seen to have predictive ability. Across the non-nested models, the Diebold and Mariano (1995) test statistic shows no perceptible difference in forecasting ability between logit and probit, except when asymmetries are introduced in the model. In that case, probit turns out to outperform the logit. Diebold and Mariano (1995) test also shows that binary choice models with and without dynamics generally perform better than Markov-switching model. However, under all evaluation criteria, the dynamic binary model which accounts for the persistence of the market states outperforms the other nested and non-nested models. Policy makers can thus use the dynamic binary model as a useful early warning tool. Furthermore, economically also, the results from active trading strategies strongly favor the market timing and active re-balancing as these accrue higher gains to the investors relative a passive strategy. It also has implications for the risk management and hedging.

As regards the macro-financial variables, different models favor different variables. However, by and large, the 5- \& 10-year term spreads, inflation, growth in Industrial Production, broad money and Fed rate stand out in all or most of the static as well as dynamic specifications. The dynamic model containing lagged dependent variable perhaps provides a parsimonious set consisting of money supply, funds rate and the exchange rate - with two term spreads turning out to be marginally significant. We also note that this dynamic specification is heavily influenced by the persistence term, due to which, in the wake of recent turbulence in the financial markets, money supply and Fed rate dominate over the term spreads and inflation. However, the empirical return pattern from different active portfolios strategies suggests that the two term spreads, inflation and broad money outperform the others, which seems to make economic as well as intuitive sense. The trading strategies therefore examine the robustness of our prediction exercise in the sense of Pesaran and Timmermann (1995).

The rest of the paper is organized as follows. Sections 2-4 describe the econometric methodology used and is succeeded by section 5 where we first briefly discuss the data and then present and evaluate the empirical results. Section 6 gives the economic significance of the exercise and section 7 concludes. 


\section{Dating Bulls and Bears}

Since we are interested in predicting the bear and bull periods on the United States stock market, we first need to identify these states. However, as noted by Candelon et al. (2008), there is no consensus in the literature on the definition of these states of market. For our purpose, we take definitions by Chauvet and Potter (2000) and Sperandeo (1994). The former define bulls and bears as periods of generally increasing and decreasing market prices. The later on the other hand terms a long-term (months to years) upward price movement characterized by a series of higher intermediate (weeks to months) highs interrupted by a series of higher intermediate lows as bull market whereas a long-term downtrend trend characterized by lower intermediate lows interrupted by lower intermediate highs as bear. These definitions are appealing in both simplicity and depth. Moreover, their focus on the extreme movements makes them a good choice for our purpose since we consider only the two states, bulls and bears. Furthermore, these are also in line with the business cycle literature that considers two states of recessions and expansions. Specifically, these are consistent with Burns (1946) definition of business cycles that focuses on the turning point in the sample path of the time series. The definitions also take care of the intermediate price falls and rises during the bull and bear strings.

Once the concept of stock market bulls and bears is clarified, the next step consists in dating them. Two approaches, i.e. a parametric and non-parametric, exist.

\subsection{Parametric Dating - Markov Switching Model}

Parametric dating method is based on Markov-switching model (MSM), introduced in economics by Hamilton (1989). Hamilton and Lin (1996); Maheu and McCurdy (2000) and Chen (2009) use this approach for stock market to identify bulls and bear regimes in order to study the volatility dynamics and make portfolio decisions.

Let $r_{t}$ represent the return on stock market index, calculated as the logarithmic change of the price index, $Y_{t}$, i.e., $r_{t}=100 \times \log \left(Y_{t} / Y_{t-1}\right)$. Let $s_{t}=i$ denote one of the two states of the variable, i.e., bear $\left(s_{t}=1\right)$ or bull $\left(s_{t}=0\right)$ market. Then a two-state Markov-switching model, where both mean $\mu_{s_{t}}$ and variance-covariance $\Omega_{s_{t}}$ vary with state $s_{t}$, is given by,

$$
r_{t}=\mu_{s_{t}}+\varepsilon_{t}, \quad \varepsilon_{t} \sim \text { i.i.d. } \quad \mathcal{N}\left(0, \Omega_{s_{t}}\right) .
$$

The state variable $s_{t}$ is assumed to be governed by first order Markov chain process whose fixed transition probabilities, $p_{i j}$, are given by:

$$
P\left\{s_{t}=j \mid s_{t-1}=i\right\}=p_{i j} \quad \forall i, j=0,1 .
$$

In particular, $p_{11}=P\left\{s_{t}=1 \mid s_{t-1}=1\right\}$ denotes the probability of starting in a bear state and ending up in the same state and $p_{00}=P\left\{s_{t}=0 \mid s_{t-1}=0\right\}$ similarly is the probability of bull state given that previous state was also a bull. The persistence of a regime can be hence calculated as $1 /\left(1-p_{11}\right)$ for bear market and $1 /\left(1-p_{00}\right)$ in case of bull state.

The parameters and the probabilities are estimated via maximum likelihood. For further analysis in the rest of the paper, we consider filtered probabilities, which represents the inference about the state variable, $s_{t}$, given information upto time $t$, i.e., $\operatorname{Pr}\left(s_{t}=i \mid r_{t}\right)$.

\subsection{Non-parametric Approach - Bry-Boschan Algorithm}

The non-parametric approach largely revolves around the algorithm developed by Bry and Boschan (1971). It was originally developed for and applied to detection of business cycles, in particular for quantitatively replicating the

contractions and expansions determined by National Bureau of Economic Research (NBER). Applications of this 
algorithm, or variants thereof, to stock market include e.g., Edwards et al. (2003); Pagan and Sossounov (2003); Candelon et al. (2008) and Chen (2009). This computer program recognizes the patterns in the time series and detaches these patterns according to a sequence of rules and locates the turning points (peaks and troughs) in the series.

Pagan and Sossounov (2003) note that the nature of asset prices is sufficiently different from real quantities so that some modifications in the original Bry-Boschan algorithm are in order. In particular, we do not smooth the series as this will entail a sufficient loss of information by eliminating the outliers which are essential features of bull and bear periods. Furthermore, this will impose an artificial structure on the data series. Other censoring criteria are as follows:

- Following Candelon et al. (2008), we set a window of six months length.

- Following Pagan and Sossounov (2003), ensure that the complete cycle lasts for sixteen months. However, we reduce phase duration to at least three months. This enables us to capture the $20 \%$ rise/fall - a threshold commonly employed in the financial press and has also been used by Pagan and Sossounov $(2003)^{1}$.

- Ensure that peaks and troughs alternate.

- In case of multiple peaks or troughs, we choose highest of the peaks and lowest of the troughs.

- Eliminate peaks or troughs within three months of beginning and end of the series.

With these guiding principles, the location of turning points amounts to identifying local maxima or minima within a window of six months. Precisely, the turning point would be a peak at time $t$ if, $y_{t-6}, \ldots, y_{t-1}<y_{t}>$ $y_{t+1}, \ldots, y_{t+6}$ and a trough if, $y_{t-6}, \ldots, y_{t-1}>y_{t}<y_{t+1}, \ldots, y_{t+6}$. Periods from peak to trough are marked as bear while those from trough to peak as bull.

\section{Models to predict bears}

Once the bear periods are defined, the ultimate goal of our paper, i.e. their predictability, can be set up.

\subsection{Linear Predictive Regressions}

The linear model complemented with exogenous macro-financial variables $\left(x_{t}\right)$ constitutes the simplest predictive regression model:

$$
P_{0, t+k}\left(s_{t}=i \mid r_{t}\right)=\alpha+\beta x_{t}+u_{t+k} \quad \forall u_{t} \sim \mathcal{N}\left(0, \sigma^{2}\right),
$$

where $P_{0}$ is the filtered probability of bear from Markov-switching model (1).

\subsection{Binary Choice Models}

Binary choice models assume that bulls and bears on the stock market can be modeled by a binary $S_{t}$ variable, i.e. the market is in either a bull $\left(S_{t}=0\right)$ or a bear $\left(S_{t}=1\right)$ state. The applications of simple probit model for predicting bears on the stock market in order to time the portfolio re-balancing include, e.g., Resnick and Shoesmith (2002); Chen (2009). In this study, however, we also apply a dynamic specifications, proposed in Kauppi and Saikkonen (2008), and use (individually) a battery of macroeconomic variables to forecast the bear market.

\footnotetext{
${ }^{1}$ Furthermore, as suggested by Lunde and Timmermann (2004) we also tried detecting the peaks and troughs without any restriction on the phase duration but the results were not different.
} 
The theoretical relationship between $S_{t}$ and macro-variable $x_{t}$, in its simplest form, can be expressed as:

$$
S_{t+k}=\alpha+\beta x_{t}+\varepsilon_{t+k} .
$$

We are interested in predicting the probability of bear condition on market, given the information about the macro-variable $x_{t}, S_{t-1}$ and parameter set $\boldsymbol{\theta}=(\alpha, \beta)$ i.e.,

$$
P\left(S_{t+k}=1 \mid x_{t} ; \boldsymbol{\theta}\right)=\boldsymbol{F}\left(\boldsymbol{x}_{\boldsymbol{t}}, \boldsymbol{\theta}\right),
$$

where $\boldsymbol{F}($.$) is any known function. There are many choices for \boldsymbol{F}($.$) , but we shall consider the two commonly$ used, viz., standard normal, $\Phi(z)$, and logistic, $\Lambda(z)$, distributions leading to Probit and Logit models, respectively.

If we let $\boldsymbol{\pi}_{t}=\alpha+\beta x_{t}$, and $p_{t}$ denotes the probability of observing a bear state $\left(S_{t}=1\right)$ at time $t$, then $S_{t}$, being dichotomous, follows a Binomial distribution with conditional expected value equal to $p_{t}$.

Formally, let $\mathfrak{F}_{t}=\sigma\left\{\left(S_{s}, x_{s}\right), s<t\right\}$ be the information set available at time $t$. Then, $S_{t} \mid \mathfrak{F}_{t-1} \sim \mathcal{B}\left(p_{t}\right)$, conditioned on $\mathfrak{F}_{t-1}$. Assuming that $\boldsymbol{\pi}_{t}=\boldsymbol{F}^{-1}\left(p_{t}\right)$,

$$
E_{t-1}\left(S_{t}\right)=P_{t-1}\left(\pi_{t}>\varepsilon_{t}\right)=P_{t-1}\left(S_{t}=1\right)=\boldsymbol{F}\left(\boldsymbol{\pi}_{t}\right)=p_{t}
$$

Dynamics can be introduced in the process $\boldsymbol{\pi}_{t}$ in four ways:

1) That periods of rise and fall of prices on stock market are persistent is an stylized fact (e.g., Guidolin and Timmermann (2005) and Candelon et al. (2008)). In terms of our definition of bulls and bears that is based on movements of stock prices, this means that these states would also be persistent. Therefore, adding lagged values of $S_{t}$ would be useful. The resulting specification then is:

$$
\boldsymbol{\pi}_{t}=\alpha+\sum_{j=1}^{r} x_{t-j} \beta_{j}+\sum_{j=1}^{q} S_{t-j} \delta_{j}
$$

2) Sequel to the reasoning in 1) above is the addition of lagged values of $\boldsymbol{\pi}_{t}$, which would add extra explanatory power to the right hand side. Although knowledge of lagged $S$ gives connotation of general state of the stock market, knowledge of lagged $\boldsymbol{\pi}$, which should account for all the information, implies the severity of the situation. Guidolin and Timmermann (2005) conclude for the UK stock and bond markets that in the short run the perceived state probability has a large effect on the optimal asset allocation. With this addition, $\boldsymbol{\pi}_{t}$ dynamics becomes:

$$
\boldsymbol{\pi}_{t}=\alpha+\sum_{j=1}^{r} x_{t-j} \beta+\sum_{j=1}^{q} S_{t-j} \delta_{j}+\sum_{j=1}^{p} \pi_{t-j} \gamma_{j} .
$$

3) The behavior of many of the macro-variables has been noted to be asymmetric during different phases of business cycle (Neftci (1984); Hamilton (1989)). For example, interest rate, output, unemployment shocks are more severe during recessions than in the expansionary periods and so is the impact of monetary policy during the two phases. Therefore, the behavior of these variables is essentially influenced by the lagged state of the economy. Given that stock market is forward looking and that changes on stock market precede the changes in the real sector, adding the interaction of lagged macro-variable $x_{t-1}$ and lagged $S_{t-1}$ would add richness to the relationship. With this augmentation, the model becomes:

$$
\boldsymbol{\pi}_{t}=\alpha+\sum_{j=1}^{r} x_{t-j} \beta+\sum_{j=1}^{q} S_{t-j} \delta_{j}+\sum_{j=1}^{p} \pi_{t-j} \gamma_{j}+S_{t-1} . x_{t-1} \xi .
$$

4) Related to 3) above, as knowledge of $p_{t-1}$ conveys the message about the severity of the state, an interaction 
of $p_{t-1}$, rather than $S_{t-1}$, with $x_{t-1}$ may also be useful.

For estimation of parameters in aforementioned specifications, we rely on the method of maximum likelihood (ML). This method is the most widely used for estimation of non-linear models, although Chauvet and Potter (2001) use Bayesian approach. The latter approach is computationally demanding whereas ML is mathematically more amenable, easy to apply and, formally, asymptotically efficient and consistent. Also, ML estimators have minimum variance in the class consistent and asymptotically normally distributed estimators.

Let $\Theta=(\alpha, \beta, \delta, \gamma, \xi)$ be the vector of parameters, then the relevant log likelihood function to be maximized is,

$$
l(\Theta \mid \mathbf{S})=\sum_{t=1}^{T}\left(S_{t} \log \boldsymbol{F}\left(\pi_{t}(\Theta)\right)+\left(1-S_{t}\right) \log \left[1-\boldsymbol{F}\left(\pi_{t}(\Theta)\right)\right]\right),
$$

where $\pi_{t}(\Theta)$ is given by right hand side of $(4),(7),(8)$ or (9). In case specifications (8) or (9) is used, $\pi_{t}$ needs to be initialized. Following Kauppi and Saikkonen (2008), we use unconditional mean of $\boldsymbol{\pi}_{t}$. That is, if $p=q=r=1$, $\pi_{0}=\left(\delta_{1} \bar{S}+\beta_{1} \bar{x}+\xi \bar{S} \bar{x}\right) /\left(1-\gamma_{1}\right)$.

\subsection{Markov-switching Regressions}

Apart from extracting the filtered probabilities via (3), it is also possible to estimate and filter out the state probabilities via a Markov-switching regression as follows:

$$
r_{t}=\alpha_{s_{t}}+\beta_{s_{t}} x_{t}+\varepsilon_{t}, \quad \varepsilon_{t} \sim \text { i.i.d. } \quad \mathcal{N}\left(0, \Omega_{s_{t}}\right) .
$$

where the estimation of the state probabilities now depends not only on the regimes and regime dependent volatility but also the exogenous regressors $x_{t}$, which in our case represent the macro-financial variables. The estimation is carried out as described in section (2.1), except that $\left(\mu_{s_{t}}\right)$ is now replaced by the right hand side of (11), $z_{t}=\left(s_{t}, x_{t-1}, r_{t-1}\right)$ and $\boldsymbol{\theta}=\left(\alpha_{0}, \alpha_{1}, \beta_{0}, \beta_{1}, \Omega_{0}, \Omega_{1}, p_{00}, p_{11}\right)$. We use this specification to extract bear probabilities and compare these with the probabilities generated by the binary choice models (BCM), described in section (3.2). Furthermore, since estimation/forecast of bear probabilities from BCM spans over multiple horizons, we need comparable probabilities from model (11) as well. We achieve this as in (12), which is the probability of observing at least one bear market over next $k$ periods. (see Candelon et al. (2012))

$$
\begin{aligned}
P\left(s_{t+1 \ldots t+k}=1 \mid z_{t}\right) & =1-P\left(s_{t+1 \ldots t+k}=0 \mid z_{t}\right) \\
& =1-\left[\left(p_{10} p_{00}^{k-1} P\left(s_{t}=1 \mid z_{t}\right)\right)+\left(p_{00}^{k} P\left(s_{t}=0 \mid z_{t}\right)\right)\right] .
\end{aligned}
$$

\section{Evaluating the Models}

\subsection{In-sample Inference}

In order to assess the predictive power of the macro-variables as well as the model, we rely on traditional evaluation strategy. In linear models we test the parameter significance via $t$-test while for binary choice and markov-switching regression models respectively, the Wald and $z$-tests are employed. For Wald-test, an heteroskedasticity and autocorrelation consistent (HAC) robust covariance estimator for parameters is employed. As to goodness of fit of the model, the $R^{2}$ for linear and pseudo- $R^{2}$ proposed by Estrella (1998) is used for binary models. Furthermore, in non-linear models, we also employ likelihood value and Akaike and Bayesian Information Criteria (AIC $\&$ BIC) as suggested by Greene (2008). 


\subsection{Out-of-sample evaluation}

To help guard against the curse of having mined the data, as conventional wisdom holds, we also consider out-ofsample test for predictability. For linear models we use Clark and West (2007) test. For non-linear models, we use a battery of test statistics proposed by Candelon et al. (2012). These include the Quadratic Probability Score (QPS), Log Probability Score (LPS), Kuiper's Score (KS), Pietra Index (PI), Bayesian Error Rate (ER) and Area Under ROC (Receiver Operating Curve) (AUC). (see Candelon et al. (2012) for description of these metrics). Incidentally, KS, AUC and PI have positive orientation meaning that a higher value implies a better fit, while QPS, LPS and ER are negatively oriented.

\subsection{Forecast comparison of models}

For the nested models, we focus on the conventional criterion of minimum Mean Squared Prediction Error (MSPE). Usually, a parsimonious (restricted) model under the null hypothesis is compared with a larger one that nests the null model. Then naturally a model with lower MSPE is favored. Clark and West (2007) maintain that under the null that parsimonious model generates the data, the larger model introduces noise into its forecasts by estimating parameters whose population values are zero resulting in a smaller MSPE for the parsimonious model. Thus, Clark and West (2007) propose an adjustment to the MSPE by subtracting the sample average of the squared difference between the forecasts from parsimonious and large models from the MSPE of larger model. They also report that MSPE-adj has more power than the extant tests. We therefore use MSPE-adj to compare out-of-sample predictability of competing nested models.

For model (3), we consider the restricted (nested) and the unrestricted models as under:

$$
\begin{array}{r}
P_{0, t+k}\left(s_{t}=i \mid r_{t}\right)=\alpha_{1}+e_{1, t+k}, \\
P_{0, t+k}\left(s_{t}=i \mid r_{t}\right)=\alpha_{2}+\beta x_{t}+e_{2, t+k} .
\end{array}
$$

We then divide the total sample $(T)$ into two portions, i.e., in-sample, $Q$, and out-of-sample, $R$. Forecasts can be made either by a rolling or a recursive scheme. We use the latter scheme, which makes it possible to use full set of available information up to the time the forecast is made.

Let $\hat{P}_{0, t+k}^{1}$ and $\hat{P}_{0, t+k}^{2}$ be the $k$-step ahead forecasts from models (13) and (14) with corresponding forecast errors of $\hat{e}_{1, t+k}$ and $\hat{e}_{2, t+k}$, respectively. Let $\hat{f}_{t+k}=\hat{e}_{1, t+k}^{2}-\left[\hat{e}_{2, t+k}^{2}-\left(\hat{P}_{0, t+k}^{1}-\hat{P}_{0, t+k}^{2}\right)^{2}\right]$ be the adjusted MSPE with the corresponding sample average of $\bar{f}=R^{-1} \sum_{t=R}^{T} \hat{f}_{t+k}$. Let also $V_{M S P E}$ be the variance of MSPE-adjusted. Then MSPE-adj statistic s given by:

$$
\text { MSPE-adj }=\sqrt{R} \bar{f} / \sqrt{V_{M S P E}} .
$$

The MSPE-adj follows asymptotically the normal distribution, therefore, the usual decision criterion applies. Moreover, this is the test for equal predictive ability of two models with an alternative favoring the unrestricted model hence a rejection will lead conclusion that the larger model has lower MSPE and exhibits better predictive content.

We also perform the Clark and West (2007) test for the probit and logit models where the simple static model of the form (5) is compared with the dynamic specifications (7), (8) and (9) or variants thereof.

Diebold and Mariano (1995) proposes a test for equal predictive accuracy of forecasts from competing non-nested models. Let $e_{i t}$ and $e_{j t}$ be the forecast errors (loss) from two forecasts $\hat{y}_{i t}$ and $\hat{y}_{j t}$ for $y_{t}$. Let an arbitrary loss function corresponding to the forecasts be $g\left(e_{i t}\right)$ and $g\left(e_{j t}\right)$ respectively. Let also $d=g\left(e_{i t}\right)-g\left(e_{j t}\right)$ be the loss 
differential, assumed to be co-variance stationary, short memory and asymptotically normally distributed. Then the null of equal predictive accuracy implies that $E\left[d_{t}\right]=0$ and the DM test statistic, which has asymptotic standard normal distribution, is given by:

$$
D M_{1}=\frac{\bar{d}}{\sqrt{2 \pi \hat{f}_{d}(0) / T}},
$$

where $\bar{d}$ is the mean loss differential and the denominator denotes the standard deviation of $d$, with $\hat{f}_{d}(0)$ being its estimate of the spectral density at frequency 0 , i.e., $2 \pi \hat{f}_{d}(0)=\sum_{\tau=-(T-1)}^{T-1} 1\left(\frac{\tau}{S(T)}\right) \hat{\gamma_{d}}(\tau)$, where $\hat{\gamma}_{d}(\tau)=$ $(1 / T) \sum_{t=|\tau|+1}^{T}\left(d_{t}-\bar{d}\right)\left(d_{t-|\tau|}-\bar{d}\right)$ and $S(T)$ is the truncation lag. We calculate the consistent estimate of the long run variance of $d$ as in Newey and West (1987). However, rather than letting the truncation lag depend on sample size, we let it correspond to the forecast horizon as suggested by Diebold and Mariano (1995).

Selecting the loss function, $g($.$) , to be quadratic, we carry out pair-wise tests of different specifications of Logit$ and Probit models as well as with the Markov-switching regression (11) for varied forecast horizons. Incidentally, the alternative hypothesis for the test is that the first model performs better than the second.

\section{$5 \quad$ Empirical Results}

\subsection{Data}

The data pertains to the United States economy. We attempt to explain the fluctuations on the stock market, using monthly S\&P 500 index, from 1957:M1 to 2011:M12, with macro-financial variables. The S\&P 500 index has been extracted from the IMF's International Financial Statistics (IFS) via Thomson Datastream.

Drawing on the existing literature, our choice of macro-financial variables follows the theoretical, economic and intuitive relation that the stock market fluctuations have with the financial and real sectors of the economy as well as those that serve as a proxy for the forces that drive the price levels on the market. The macro-financial variables we consider therefore are: 10 and 5 year term spreads (i.e., the difference between the short term rate on 3-month maturity treasury bill and 10- \& 5-year treasury constant maturity rates); growth rates (log differences) for consumer price index, narrow money (M1), broad money (M2) and industrial production; and changes (differences) of Federal Funds, unemployment and nominal effective exchange rates. These variables, also at monthly frequency, are obtained from Federal Reserve Economic Data (FRED-II) via Federal Reserve Bank of St. Louis website ${ }^{2}$. Furthermore, all macro-financial variables also cover period 1957:M1-2011M12 except M1 \& M2 and Exchange Rates which are for the periods 1959:M1-2011:M12 and 1975:M1-2011:M12, respectively.

\subsection{Linear Predictive Regression Models}

We first discuss the in-sample results. Panel A of table 1 reports the results from two regression models: i) a linear model of stock market returns with drift $(\mu)$ and ii) a Markov-switching model where both drift $\left(\mu_{s_{t}}\right)$ and variance $\left(\sigma_{s_{t}}\right)$ dependent on state of the stock market. The switching regime model seems better than the linear model as judged from the value of likelihood function. It is clear that latter model is better than the former in having a higher likelihood value. The log likelihood ratio is too large to be statistically insignificant ${ }^{3}$. As would be expected, mean returns are lower (even negative $0.989 \%$ ) in bear periods while higher (positive 1.064) during bulls. Furthermore, the risk becomes higher $\left(\sigma_{1}=6.183\right)$ during stock market downturns and lower $\left(\sigma_{0}=3.175\right)$ during the

\footnotetext{
${ }^{2}$ http://research.stlouisfed.org/fred2/

${ }^{3}$ Although plagued by nuisance parameter thus making conventional LR test inapplicable, the LR statistic is way higher than the empirical critical values reported by Garcia (1998).
} 
upturns. That volatility is non-constant during upturns and downturns on the stock market is a stylized fact of stock market returns (see Maheu and McCurdy (2000); Cunado et al. (2008) and refernces therein). Moreover, the boom period lasts longer than busts. On average, a boom persists for seventeen $([1 /(1-0.942)]=17)$ months whereas a bust lasts seven $([1 /(1-0.845)]=7)$ months . This is also in agreement with the finding in the literature (see e.g., Gonzalez et al. (2005); Chen (2009)).

Table 1 about here

Having estimated the Markov-switching model, we filter the probabilities of bear state $\left(s_{t}=1\right)$ at time $t$, using the information available at that time. Figure 1 shows these probabilities. There seem to be quite a few spikes. If a threshold of $50 \%$ is used, market turmoil when the S\&P 500 index dips, are captured quite well. However, the signals tramsitted by these probabilities are non-synchronous to the actual dips in the index.

Figure 1 about here

On the basis of filtered probabilities, we then move on to explain the fluctuations therein with macro-financial variables via predictive regression (3). Panel $\mathrm{B}$ of table 1 reports the results from this regression for predictability over 1,3 and 12 months horizons $(k)^{4}$. Only inflation turn out to be significant predictor for at all horizons. As to the other variables, 5-year term spread, industrial production growth, narrow money (M1), and changes in unemployment and fund rates show predictability at short horizons ${ }^{5}$, while two term spreads and broad money supply growth (M2) reveal forecast ability at longer horizons. One noteworthy thing is that although predictability can be inferred from the significance level of the parameter estimates, the amount of variation explained by all variables, $R^{2}$, is hardly impressive - the maximum being 6\%. The results suggest that the United States stock market is quite sensitive to the news about the changes in inflation rate as well as interest rates. A positive relationship of the interest rate spreads ${ }^{6}$ and inflation with the onset of bear conditions on the stock market is quite intuitive and expected of a developed market like United States. In fact yield spread has empirically been found to be quite strong and consistent forecaster for the recessions (see for example Estrella and Mishkin (1998); Chauvet and Potter (2001); Kauppi and Saikkonen (2008)). Therefore its significance for the stock market busts seems quite obvious. Theoretically also, since equity prices reflect the discounted future cash flows, the expected return plays a vital role in determinations of the direction of change in prices. A rising term spread would imply higher longer term rates and the market's expected rate would accordingly increase to match the movement. This would in turn put downward pressure on the prices. A persistent term spread rise would thus be a harbinger of bear conditions on the stock market. Furthermore, the inflation being added premium in the interest rate - Fisher relation - should have same consequences (see e.g., Bordo et al. (2008)). Recently, Rapach et al. (2005) also report the similar results for spreads and inflation in case of return predictability in the US market. They find that inflation is significant over all horizons, however, the spread does not show predictability for the longer horizons in their specification. For other variables, the results are also similar. Regarding the significance of inflation, Rapach et al. (2005); Chen (2009) argue that supply shocks seem to be important for the United States. It may also be mentioned that while Fama (1981); Geske and Roll (1983) found a negative relation between stock market returns and inflation, the market fluctuations in our empirical exercise are however expectedly positively related.

\footnotetext{
${ }^{4}$ We actually estimated predictive regression model, as well as subsequent models, for 1, 3, 6, 12 and 24 month horizons. However, in the interest of space we report results for only 1, 3 and 12 horizons. Nonetheless, to give an idea about which variables are significant predictor at what horizon $(k)$, we summarize the results for all $k$ and for all models in table 7 . Therefore, to get better understanding of the predictive behavior of the macro-financial variables, tables $1 \& 3-6$ may be read in conjunction with table 7 . Detailed results can be requested from the authors.

${ }^{5}$ To set the stage, short, medium and long term/horizons are with respect to our considered forecast horizons. Specifically, we term $1 \& 3$ months as short, 6 as medium and $12 \& 24$ months as long term.

${ }^{6}$ Just to recap, please note that we have defined the spreads as the difference between the 3-month treasury rate and the $5 \& 10$ years rate on government securities.
} 
In order to test the out-of-sample predictability of macro-financial variables in (3), we conduct the adjusted Mean Squared Prediction Error (MSPE-adj) test for nested models proposed in Clark and West (2007). In our case, we compare the forecasting power of a parsimonious model (13) with a more general model (14), which nests the latter. Recall that this is a test for equality of predictive errors from both models with the alternative favoring the unrestricted model. The column captioned $C W$ in Panel B of table 1 provides the results. While the MSPE-adj test generally corroborates the results from predictive regression (3), except for narrow money and exchange rate, all the variables show usefulness to forecast bear conditions nearly for all horizons.

\subsection{Binary Choice Models}

Estimation of the binary choice models $(\mathrm{BCM})$, requires a series of bull and bear periods in the form of an indicator $(0 / 1)$ variable. We achieve this by first subjecting the aggregate US stock market index, S\&P 500, to Bry and Boschan (1971) algorithm, thereby identifying the turning points. We then label periods from peak to trough as bear, $S_{t}=1$, and periods from trough to peak as bull, $S_{t}=0$. We thus obtain a series over the period of estimation indicating the bear and bull market states. Figure 2 plots this indicator variable alongside the S\&P 500 index. The algorithm successfully captures the dips in the index from 1957M1 to 2011M12. Furthermore, our identified bear phases largely conform to those obtained by Pagan and Sossounov (2003) and Gonzalez et al. (2005) over their respective periods of estimation.

Figure 2 about here

In section 5.2 we discussed the results of linear regression of the filtered probabilities from Markov-switching model on the macro-variables. We observed that although some variables could explain the variation, however, the overall fit of the model $\left(R^{2}\right)$ was quite low. In this section, we report and discuss the results from binary choice models (BCM), both in- and out-of-sample, in an attempt to see whether simple BCMs or inclusion of dynamics therein pays off.

The BCMs are in essence nonlinear models and we expect it to discern some hidden non-linearities in the data which the simple linear model could not have detected. Our estimation results revolve around the specifications (7), (8) and (9) and/or combinations thereof. Our benchmark model is a simple binary model, $P_{t-k}\left(S_{t}=1\right)=\boldsymbol{F}\left(\boldsymbol{\pi}_{t}\right)$, where $\boldsymbol{\pi}_{t}$ is of the form (17) with $x_{t-k}$ denoting the macro-financial variable used to forecast $k$ periods ahead.

$$
\pi_{t}=\alpha+x_{t-k} \beta
$$

We start by looking at the in-sample results of benchmark model (17). Table 2 displays the results in case of probit model ${ }^{7}$ for forecast horizons 1,3 and 12 months $^{8}$. In this as well as in all the subsequent tables giving estimation results from various Probit models, we report the parameter estimate(s) excluding constant, the Wald test $p$-value that $\hat{\theta}=0$, the pseudo- $R^{2}, A I C$ and $B I C$ for in-sample fit. For out-of-sample evaluation, we report the quadratic probability, log probability and Kuiper's scores, Pietra index, error rate and area under ROC. The empirical results from simple probit model (17) in table 2 are a bit different from those of linear regression model (3) in table 1. In terms of Wald test $p$-value, besides inflation the two term spreads and the inflation are now significant predictors for all horizons. Additionally, industrial production and exchange rate are useful for short horizons whereas the broad money supply (M2) and changes in unemployment rate give better fit for medium and longer horizons, respectively. Out-of-sample statistics also support the in-sample fit. Interestingly, nothing is gained

\footnotetext{
${ }^{7}$ We estimated Logit model as well, but the results are not included to conserve space.

${ }^{8}$ As with linear regressions, we also carried out estimation and prediction for 1, 3, 6, 12 and 24 month horizons. But due to space constraints we only report results for 1, 3 and 12 month horizons. Detailed results are available from the authors upon request. However, summary results are reported in table 7
} 
even in terms of either in-sample fit, as pseudo- $R^{2}$ is still quite low for all models (max of $4 \%$ ). For out-of-sample, for example, KS is close to zero and AUC is hardly over 0.5 , showing random nature of forecasts. ${ }^{9}$. We, therefore, progressively move on to include dynamics in model (17).

Tables 2 about here

Our first inclusion is the lagged market state indicator $\left(S_{t-q}\right)$. For probit, we report in table 3 the results from model (7) with first lag of $S_{t}{ }^{10}$. The fit increases quite dramatically to approximately $76 \%$ and the two information criteria also signifcantly improve. For all the variables and at all horizons, the lagged bear market indicator turns out to be highly significant. The downside, though, is that the macro-financial variables loose their predictive power, with exception of the two measures of money supply (M1 \& M2), Fed funds rate and exchange rate, which are significant for short horizons. Broad money supply and exchange rate show significance for medium horizons while no variable turns out to be significant for longer horizons. The results from this model convey two messages: first, that the lagged bear market indicator is significant at all horizons irrespective of macro-financial variable used, strongly points to the fact that stock market regimes are autocorrelated and hence persistent! Once this fact is taken care of, the explanatory power of the model increases sharply. Second, since our data sample contains the episode of recent global economic upheaval due to turmoil in the subprime mortgage market in the US, significance of money supply as well as fed funds rate points to the effectiveness of the quantitative easings (QEs) as well as response of the market towards changes in the policy interest rate by the US Federal Reserve (see e.g., Lothian (2009)). A closer look at the behavior of money supply growth reveals that whereas during the previous bear periods its growth declined or inched up moderately, the level of growth during past three episodes (2000-2002, 2007-2009 and 2011) has been very pronounced, especially during the two recent downturns. This latter surge coincides with the QEs. Furthermore, since the model strongly refelects the persistence and we use the most recent one, i.e., $S_{t-1}$, it is also intuitive that the funds rate is significant. Its significance implies market's response to Fed's commitment to keep the rates depressed - hence the effectiveness of monetary policy. The upside then is that this model adequately captures the state dependnce and provides a parsimonious set of exogenous variables to focus on. But, does this mean that term spread and inflation are no longer useful? Perhaps not! first, the two spreads are still significant though marginally at $10 \%$ level. Second, theoretically, it can be argued that an expansion in money supply is expected to lead to a lower real rate of interest in the short run. However, in the long run the rate would increase if premium due to inflation is expected to rise. Thus slope of the yield curve should imply the expected market conditions. However, during the current crisis the Fed both increased the money supply as well as reduced its policy rate, while at the same time it asserted its commitment to price stability. This, coupled with the fact that the market was dry of liquidity, resulted in the expectations about spread and inflation being subdued. Furthermore, as the model emphasizes more on the persistence and state contingency, the news about money supply and policy rate dominated.

Regarding the out-of-sample results, surprisingly, the statistics from all criteria is approximately the same. This may be due to the fact that the lagged dependent variable as an explanatory element possibly overrides the other exogenous variables.

Tables 3 about here

Encouraged by the statistical evidence for persistence of market conditions, we now test whether the perceived past beliefs (probability) of market fluctuations, $\pi_{t}$, have any impact. We already argued that $\pi_{t}$ implies the sense of severity of the regime. Therefore, inclusion of lagged autoregressive term may add value to the forecast ability.

\footnotetext{
${ }^{9}$ The results in case of logit model for this specification as well as the latter dynamic specifications are essentially the same in terms of significance and other model considerations and, therefore, are not reported in the interest of space.

${ }^{10}$ We also tested higher lags but no perceptible gain in terms of fit or likelihood value was observed. In some instances, , even deterioration was observed
} 
Table (4) gives the results for probit from specification where $S_{t-1}$ is replaced by the autoregressive term, $\pi_{t-1}$. Interestingly, all the macro-variables now bear forecast ability for varied horizons - i.e., some useful for short horizon while the others for the medium and long ones. The results support the assertion that it is the perception and anticipation about the market conditions that move the price levels induced by, inter alia, the changes in macroeconomic conditions as implied by various macro-financial variables. The broad money growth turns out to be significant in this specification as well, but now for all horizons. This coupled with the Fed rate possibly points to the response to monetary policy by the market. The nominal effective exchange rate is also positive and significant for all horizons. The empirical relationship between stock market and exchange rates is however contentious. Ajayi et al. (1998); Roll (1992) report positive relationship while Nieh and Lee (2001) find no significant long run or short run relationship for the United States. The out-of-sample results correspond to those of in-sample ones, although not as better. In some case the value of AUC statistic around 0.5 shows random nature of forecast from the model, similar to the static probit.

Tables 4 about here

Our final inclusion is the lagged interaction term of the explanatory and the dependent variables, i.e., $x_{t-p} . S_{t-q}$. We consider the first lag of the interaction term, i.e., $p=q=1$. The results are reported in table 5 . Both spreads show predictability for all $k$ 's, while inflation, growths in industrial production and money supply again turn out to be significant for either short or long of the considered horizons. The change in unemployment is significant and negative at middle of the considered horizons (not reported in the table). This may point to the asymmetric response of this variable which is a well documented (see e.g. Boyd et al. (2005)). On downside, the value of pseudo- $R^{2}$ drops and those of information criteria increases compared with specification with $S_{t-1}$ (see table 3 ). However, there is still an impressive improvement compared with both the static as well as the autoregressive probit specifications (see tables 2 and 4). That the interaction term also remains significant alongside the exogenous macro-financial variables, again point to the regime persistence and the state contingency of the different economic variables. The out-of-sample fit, compared with the in-sample results, is stronger for those variable which are significant in-sample. For example, for industrial production the $R^{2}$ is just $3 \%$ but the AUC is $62 \%$. Same goes for two term spreads and inflation. This may be due to the fact that since interaction terms captures the asymmetric content of the explanatory variable, this iformation also turns out to be useful for out-of-sample forecasting.

Tables 5 about here

\subsection{Markov-switching regression model}

Finally, in this sub-section, we discuss the estimation results from a Markov-switching model where we extract the state probabilities from the S\&P 500 returns conditioned on an exogenous macro-financial variable (see model (11)). The results are reported in table 6. The 10-year spread shows marginal significance (at 10\%) for the bear state, possibly showing sensitivity and ability of the it to imply bad times. Unemployment, funds rate and the nominal exchange rate are significant for the bull state only. None of the variables, under this specification, is able to predict both states. Although the fit of the model as judged from the likelihood and AIC, BIC values is not much impressive, the results point to the asymmetric nature of some variables. This could imply that 10-year spread is a useful indicator for the bear markets, whereas the information content of unemployment, funds and exchange rates show import for the rising market conditions. Another implication from the general conditional insignificance of these macro-financial variables is the potential difficulty of return predictability using these variables - since the dependent variable is the market returns (see model 11). On the other hand, state-contingent nature of some other variables point to their usefulness in predicting the direction of the market.

Table 6 about here 
For the out-of-sample evaluation, we again use same criteria as in binary choice models. These statistics are reported in last six columns of table 6. Although the out-of-sample statistics for macro-variables support those in in-sample, the best out-of-sample performance is by the growth in industrial production. QPS, LPS and ER have comparatively lower values for industrial production, at same time it has higher PI and AUC value. This is intuitive as generally the growth in industrial production - a proxy for output level - has implications for the state of the economy, and hence for the stock market. Generally, the out-of-sample results for Markov-switching model (11) are not encouraging when compared with the binary choice models.

\subsection{Comparison of forecasts}

In this section, we compare the inter- as well as intra-model forecasting ability of different models. We report results from Clark and West (2007) test for nested models and Diebold and Mariano (1995) test for non-nested models.

Panel A of table 8 reports the results of equal forecast ability between simple static model of the form (17) and various dynamic specifications for Probit model. In line with the out-of-sample results, dynamic specifications with lagged term, $S_{t-1}$, always, and interaction term, generally, stand out. Although not as better, the autoregressive specification also outperforms the static model. The results are similar for logit as can be ascertained from Panel $\mathrm{B}$ of the table. This clearly demonstrates that augmenting the static model with additional dynamics is a value addition.

Table 8 about here

For the non-nested models, we first compare the probit and logit models across different specifications and horizons. Columns 2-5 of table 9 show that we cannot reject the null of equal predictive performance of two models, except for the interactive dynamic model (XZ). In case of model XZ, except for industrial production, Fed funds and exchange rates, the probit outperforms the logit.

Table 9 about here

The results for forecast comparison of binary response models with Markov-switching regressions in table 9 convincingly reject the equal accuracy null in case of dynamic probit and logit models (XY). However, for other specifications, we fail to reject the null at short horizons for some variables, whereas for longer horizons the null hypothesis is again rejected, except in case of exchange rate where these models perform as good as the Markovswitching model. This shows that excepting a few variables at short horizons, binary response models outperform the Markov-switching model. Birchenhall et al. (1999) and Candelon et al. (2012), in different settings, also find that logit model performs better than Markov-switching specification.

Overall, the macro-financial variables offer a useful set of variables to forecast the upturns and the downturns on the stock market. Table 7 summarizes the results. Except in dynamic probit and Markov-switching models, term spreads, inflation, industrial production and unemployment stand out to be significant predictors in other specifications. Nevertheless, the dynamic probit model offers a parsimonious set of variables where money supply, funds rate and exchange rate turn out to be useful ${ }^{11}$. This model also provides an impressive fit in-sample as well as out-of-sample forecast ability versus all other models.

\section{Why Predict Bear Market?}

Significant as it is from the monetary policy and financial market regulation perspective, as a last step in this exercise, we show the utility of predicting the bear market conditions for the investors, which are generally the

\footnotetext{
${ }^{11}$ One can argue for that matter that Markov-switching model offers a more parsimonious set of macro-financial indicators than the dynamic probit model. However, recall that these variables are significant for one state of the market, i.e., the bull state (see table 6). The dynamic probit on the other hand offers a set of variables which are significant alongside the significant lagged state variable.
} 
largest consumers of such market reports. We form three active trading strategies and compare their performance with the buy-and-hold strategy - henceforth passive strategy. In each strategy we start with an investment of one dollar in December $1979^{12}$ until the end of our sample period, i.e., December 2011. To be close to reality, using each of the four Probit models (X, XY, XZ and XP) and each macro-financial variable, we recursively forecast one month ahead probability of bear market based on the information available at the time of estimation. For example, to forecast for January 1980, we use information upto December 1979; for February 1980 we use data upto January 1980 and so on, such that the information set gets bigger as we move on. We then compare this forecast probability with three thresholds $(\tau)$ viz., $40 \%, 50 \%$ and $70 \%$ to decide whether the market is in a bear or bull state. Specifically, if the forecast probability is greater than or equal to the threshold, we term the market to be in bear state and go on to active re-balancing following each strategy. The thresholds, $\tau$, may be thought of as a spectrum representing the risk-averse and risk-seeking investors.

Our first strategy, as in Pesaran and Timmermann (1995) and Chen (2009), is to invest all in 1-year treasury bond ${ }^{13}$ if a given model with a certain macro-financial variable predicts bear conditions one month ahead otherwise invest all in S\&P500 index. This switching strategy would be ideal for the institutional investors, e.g., pension funds, who would like to exploit the market expectations while at the same time prefer to trade in liquid securities. The second strategy is to capitalize on the information about forecasted bear conditions and go short when market is predicted to enter bear state and stay long otherwise. This long/short strategy is hedge funds' favorite and is exploited by around $40 \%$ funds (Fung and Hsieh (2011)). Finally, the third strategy is for those (possibly individual) investors who want to trade judiciously on the stock market by following the market movements. The strategy is to buy when the model forecasts a trough and sell when the market is at the peak. This means that investors are in the market in normal or bull conditions but are out of market in turbulent times. This ternd-following strategy is the implementation of buy-low-sell-high, an ages old golden rule on the stock market ${ }^{14}$ (Dai et al. (2010)).

Incidentally, one of the criticism on such active strategies is that these do not account for transaction costs. To address this concern, we take a transaction cost of 50 basis points when trading in stocks while the cost for bonds is 10 basis points (Pesaran and Timmermann (1995); Balduzzi and Lynch (1999); Han et al. (2011); Pollin and Heintz (2011)). Furthermore, in the long/short strategy, the costs are 100 basis points for going short as this is often costly (see Diether et al. (2009) and references therein) ${ }^{15}$.

The results of the exercises are reported in table 10. Panel A of the table shows the monthly compound return from passive strategy as well as return from a similar strategy when investing in a 1-year treasury security. The former will form our benchmark for comparing the returns accrued from an active re-balancing via each of the above strategies. The results from the active trading strategies are given in panel B of the table.

Table 10 about here

First, looking at the strategies, the first one dominates the other two in terms of returns and is followed by long-short, while third strategy pays the lowest. This is intuitive as in the first strategy one would (almost) always be grabbing positive returns both during the up-states of the market from the rising stock prices as well during the down-states from the treasury investment. That's why it makes sense for the pension funds who always want to keep their portfolio liquid while at the same time strive for higher returns. In the other two strategies, the returns from

\footnotetext{
${ }^{12}$ The starting point is arbitrary. We just wanted to have enough observations to make first forecast.

${ }^{13}$ One year rate corresponds to the average duration of the bear market as implied by the Bry-Boschan algorithm

${ }^{14}$ For this last startegy, we assume that the investor has a current account with some discount broker who acts only when advised by the investor. Furthermore, the funds remain with the broker and earn zero interest. Of course the idea is that zero return is preferrable over the negative return during the down turns! This assumption makes this active staregy comparable with the passive buy-and-hold one.

${ }^{15}$ Please note that our long/short strategy is not market-neutral. Besides, we also assume that (i) the proceeds from the short-sell remain with the broker, (ii) the proceeds do not earn any interest from the broker, and (iii) the margin is settled when the short position is closed. As reported by Boehmer et al. (2008), short-selling is mostly employed by institutional investors ( $72 \%$ versus $2 \%$ individuals), the assumptions theerfore are likely to hold.
} 
the long/short strategy could have been marred by both higher transaction costs as well as the possible forecast misses, which weigh heavily on the overall return. The third strategy's return is obviously reduced by intermediate no investment episodes during the bear market. Even in this case the performance of the strategy is generally better than the buy and hold strategy. Active strategies have also been found to accrue positive (abnormal) returns by, e.g., Cohen et al. (2007) and Diether et al. (2009) (for short-selling) and Pesaran and Timmermann (1995); Marquering and Verbeek (2004) (for other related strategies).

Second, in terms of models, the strategies based on the dynamic model, XY, predominantly fetch superior returns, followed by the interactive dynamic, XZ, autoregressive, XP, and simple probit, X, models respectively. The identical returns for all the probability cut-offs from XY model should not be surprising. The model, because of its dynamics carries the persistence and predicts generally in the lowest or highest percentile of unit probability interval. This can also be ascertained from figure 4 .

Third, it is also interesting to see the return pattern offered by different macro-financial variables. The forecasts based on leading indicators like term spreads, inflation and money supply yield better results, even in static probit. The performance of other variables varies across models as well as the thresholds used, the exception being the dynamic model (XY). Interestingly, the exchange rate, which turned out to be significant in the model XY, does not provide as better results. One explanation could be its ambiguous behavior reported in the literature - i.e., both its positive as well as negative relationship with the stock market (see e.g., Ajayi et al. (1998); Nieh and Lee (2001)) - resulting in unstable forecasting pattern over different sample periods and leading to depressed returns.

Now that the active strategies based on forecasts from the dynamic Probit models consistently and convincingly outperform the passive strategy, it has also implications for the risk management and hedging. Especially, in the options market one can utilize the forecasts to either write contra-trend options or hedge ones portfolio against the possible price declines during the market downturn. For example, besides following one of the strategies, writing an out-of-money covered call when the market is expected to enter bear state would earn extra premium.

The main message from the results is: the active re-balancing based on forecasts from probit models with dynamics yields higher returns compared with the buy-and-hold strategy. Especially, the forecasts based on leading indicators like trem spreads, inflation and money supply yield better results. A threshold of $40 \%$ provides optimal results.

\section{Conclusion}

In this paper we attempt to predict the bear conditions on the US stock market via both linear as well as nonlinear techniques using macro-financial variables. We consider forecasting techniques that include linear predictive regressions, static and dynamic binary choice models as well as Markov-switching model. We extract the bulls and bears episodes using both parametric (Markov-switching) as well as non-parametric (Bry and Boschan (1971)) techniques and then explain these with aforementioned models using a set of macro-financial variables. We evaluate the in- and out-of-sample estimation results by a variety of metrics and compare the forecasting performance of various model specifications.

Our results show that various extensions of simple probit and logit models which introduce the dynamics are a useful value addition in terms of both in- and out-of-sample fit. In contrast to the linear model and simple probit/logit models, all the macro-financial variables reveal predictive content, albeit at varied horizons, when accounted for persistence and/or asymmetries through introduction of dynamics. This is tested by the Clark and West (2007) test of equal predictive ability of nested models. As to the tests across the non-nested models via Diebold and Mariano (1995) statistic, the logit and probit does not show perceptible difference in forecasting except when asymmetries are introduced in the model. In that case, probit turns out to outperform the logit. Diebold and Mariano (1995) test also shows that binary choice models with and without dynamics generally 
perform better than Markov-switching model.

The 10- and 5-year term spreads, inflation, industrial production, money supply and funds rate turn out to be significant at different forecast horizons in static as well as various dynamic specifications of binary response models. However, the dynamic binary model, which exploits the persistence of market states, provides money supply, Fed funds rate and exchange rate as significant explanatory variables. Nonetheless, when read with the results from empirical performance of the macro-financial variables in formation of active portfolios, two term spreads, inflation and money supply turn out to be a useful parsimonious set.

Finally, the results show that binary choice models with dynamics can be a useful tool for forecasting the stock market movements and hence can be utilized by policy makers as well as investors. It can be used by the regulators as an early warning tool. For the investors, the economic significance and utility has been demonstrated via different market-timing strategies. The results also have implications for risk management and hedging.

\section{References}

Ajayi, R. A., Friedman, J. and Mehdian, S. M. (1998). On the Relationship between Stock Returns and Exchange Rate: Test of Granger Causality, Global Finance Journal 9(2): 241-251.

Anatolyev, S. and Gospordinov, N. (2010). Modeling Financial Return Dynamics via Decomposition, Journal of Business and Economic Statistics 28(2): 232-245.

Balduzzi, P. and Lynch, A. W. (1999). Transaction Costs and predictability: some utility cost calculations, Journal of Financial Economics 52: 47-78.

Birchenhall, C. R., Jessen, H., Osborn, D. R. and Simpson, P. (1999). Predicting U.S. Business Cycle Regimes, Journal of Business \&3 Economic Statistics 17(3): 313-323.

Boehmer, E., Jones, C. M. and Zhang, X. (2008). Which Shorts Are Informed?, Journal of Finance 63(2): 491-527.

Bordo, M. D., Dueker, M. and Wheelock, D. C. a. (2008). Inflation, Monetary Policy and Stock Market Conditions, National Bureau of Economic Research (NBER), Working Paper No. W14019.

Borio, C. and Lowe, P. (2002). Asset Prices, Financial and Monetary Stability: Exploring the Nexus, BIS Working Papers No. 114.

Boyd, J. H., Hu, J. and Jagnathan, R. (2005). The Stock Market's Reaction to Unemployment News: Why Bad News Is Usually Good for Stocks, The Journal of Finance 60(2): 649-672.

Bry, G. and Boschan, C. (1971). Cyclical Analysis of Time Series: Selected Procedures and Computer Programs, Columbia University Press, National Bureau of Economic Reasearch, New York.

Candelon, B., Dumitrescu, E. and Hurlin, C. (2012). How to Evalutae an Early Warning System?, IMF Economic Review 60(1): 75-113. HAL, Working Paper.

Candelon, B., Piplack, J. and Straetmans, S. (2008). On Measuring Synchronization of Bulls and Bears: The case of East Asia, Journal of Banking and Finance 32: 1022-1035.

Chauvet, M. and Potter, S. (2000). Coincident and Leading Indicators of Stock Market, Journal of Empirical Finance 7: 87-111.

Chauvet, M. and Potter, S. (2001). Forecasting recessions using yield curve, Federal Reserve Bank of New York Staff Paper 134.

Chen, S.-S. (2009). Predicting the bear stock market: Macroeconomic variables as Leading Indicators, Journal $f$ Banking and Finance 33: 211-223.

Christoffersen, P. F. and Diebold, F. X. (2006). Financial Asset Returns, Direction of Change Forecasting, and Volatility Dynamics, Management Science 52(8): 1273-1287. 
Clark, T. E. and West, K. D. (2007). Approximately Normal Tests for Equal Predictive Accuracy in Nested Models, Journal of Econometrics 138: 291-311.

Cochrane, J. H. (2008a). Handbook of the Equity Risk Premium, Elsevier Science, chapter 7, pp. 237-330.

Cochrane, J. H. (2008b). The Dog That Did Not Bark: A Defense of Return Predictability, The Review of Financial Stucies 21: 1533-1575.

Cohen, L., Diether, K. B. and Malloy, C. J. (2007). Supply and Demand Shifts in the Shorting Market, Journal of Finance LXII(5): 2061-2096.

Cunado, J., Gil-Alana, L. A. and De Gracia, F. P. (2008). Stock Market Volatility in US Bull and Bear Markets., Journal of Money, Investment and Banking (1): 24-32.

Dai, M., Zhang, Q. and Zhu, Q. (2010). Trend following trading under a regime switching model, SIAM Journal of Financial Mathemetics 1: 780-810.

Diebold, F. X. and Mariano, R. S. (1995). Comparing Predictive Accuracy, Journal of Business a 13(3): 134-144.

Diether, K. B., Lee, K.-H. and Werner, I. M. (2009). Short-selling Strategies and Return Predictability, The Review of Financial Studies 22(2): 575-605.

Edwards, S., Biscarri, J. G. and de Gracia, F. P. (2003). Stock Market Cycles, Financial Liberalization, and Volatility, Journal of International Money and Finance 22: 925-955.

Estrella, A. (1998). A New Measure of Fit for Equations with Dichotomous Dependent Variables, Journal of Business \&3 Economic Statistics 16(2): 198-205.

Estrella, A. and Mishkin, F. S. (1998). Predicting U.S. Recessions: Financial Variables as Leading Indicators, The Review of Economics and Statistics 80(1): 45-61.

Fama, E. F. (1981). Stock Returns, Real Activity, Inflation, and Money, The American Economic Review 71(4): 545-565.

Fung, W. and Hsieh, D. A. (2011). The risk in hedge fund strategies: Theory and evidence from long/short equity hedge funds, Journal of Empirical Finance 18: 547-569.

Garcia, R. (1998). Asymptotic Null Distribution of the Likelihood Ratio Test in Markov Switching Models, International Economic Review 39(3): 763-788.

Geske, R. and Roll, R. (1983). The Fiscal and Monetary Linkage Between Stock Returns and Inflation, The Journal of Finance 38(1): 1-33.

Gonzalez, L., Powell, John G. amd Shi, J. and Wilson, A. (2005). Two Centuries of Bull and Bear Market Cycles., International Review of Economics and Finance 14: 469-486.

Goyal, A. and Welch, I. (2003). Predicting the Equity Premium with Dividend Ratios, Management Science 49(5): 639-654.

Goyal, A. and Welch, I. (2008). A Comprehensive Look at the Empirical Performance of Premium Prediction, Review of Financial Studies 21(4): 1455-1508.

Greene, W. H. (2008). Econometric Analysis, 6th edn, Pearson Prentice Hall, Pearson Education Inc., Upper Saddle River, New Jersey, USA.

Guidolin, M. and Timmermann, A. (2005). Economic Implications of Bull and Bear Regimes in UK Stock and Bond Returns, The Economic Journal 115: 111-143.

Hamilton, J. D. (1989). A New Approach to the Economic Analysis of Non-stationary Time Series and Business Cycles, Econometrica 57: 357-384.

Hamilton, J. D. and Lin, G. (1996). Stock Market Volatility and the Business Cycles., Journal of Applied Econometrics 11: $573-593$. 
Han, Y., Yang, K. and Zhou, G. (2011). A New Anomaly: The Cross-sectional Profitability of Technical Analysis, SSRN .

URL: $h t t p: / / s s r n . c o m / a b s t r a c t=1656460$

Kauppi, H. and Saikkonen, P. (2008). Predicting U.S. Recessions With Dynamic Binary Response Models, The Review of Economics and Statistics 90(4): 777-791.

Lamdin, D. J. (2003). Corporate Bond Yield Spreads in Recent Decades: Trends, Changes, and Stock Market Linkages, University of Maryland, Working Paper .

Lothian, J. R. (2009). U.S. Monetary Policy and the Financial Crisis, CenFIS, Federal Resrve Bank of Atlanta Working Paper No. 09-01.

Lunde, A. and Timmermann, A. (2004). Duration Dependence in Stock Prics: An Analysis of Bull and Bear Markets, Journal of Business 85 Economic Statistics 22(3): 253-273.

Maheu, J. M. and McCurdy, Thomas, H. (2000). Identifying Bulls and Bear Markets in Stock Returns, Journal of Business 83 Econoic Statistics 18(1): 100-112.

Marquering, W. and Verbeek, M. (2004). The Economic Value of Predicting Stock Index Returns and Volatility, Journal of Financial and Quantitative Analysis 39(2): 407-429.

Neftci, S. N. (1984). Are Economic Time Series Asymmetric over Business Cycles?, Journal of Political Economy 92(2): 307-328.

Newey, W. and West, K. (1987). A Simple Positive Semi-definite Heteroskedasticity and Autocorrelation Consistent Covariance Matrix, Econometrica 55: 703-708.

Nieh, C.-C. and Lee, C.-F. (2001). Dynamic Relationship between stock prices and exchnage rates for G-7 countries, The Quarterly Journal of Economics and Finance 41: 477-490.

Nyberg, H. (2011). Forecasting the direction of the US stock market with dynamic bianry Probit model, International Journal of Forecasting 27: 561-578.

Pagan, A. R. and Sossounov, K. A. (2003). A Simple Framework for Analysis of Bull and Bear Markets, Journal of Applied Econometrics 18: 23-46.

Pesaran, H. M. and Timmermann, A. (1994). Forecasting Stock Returns: An Examination of Stock Market Trading in the Presence of Tracnsaction Costs, Journal of Forecasting 13(4): 335-367.

Pesaran, H. M. and Timmermann, A. (1995). Predictability of Stock returns: Robustness and Economic significance, Journal of Finance 50(4): 1201-1228.

Pollin, R. and Heintz, J. (2011). Transaction Costs, Trading Elasticities and the Revenue Potential of Financial Transaction Tax for the United States, Research Brief - Political Economy Research Institute, University of Massachusetts, Amherst.

URL: http://www.peri.umass.edu/fileadmin/pdf/research_brief/PERI_FTT_Research_Brief.pdf

Rapach, D. E., Wohar, M. E. and Rangvid, J. (2005). Macro-variables and International Stock Return Predictability, International Journal of Forecasting 21: 137-166.

Resnick, B. G. and Shoesmith, G. L. (2002). Using the Yield Curve to Time the Stock Market, Financial Analysts Journal 58(3): 82-90.

Roll, R. (1992). Industrial Structure and the Comparative Behavior of International Stock Market Indices, The Journal of Finance 47(1): 3-41.

Shen, P. (2003). Market Timing Strategies that Worked: Based on E/P ratio of the S\&P 500 and interest rates., Journal of Portfolio Management 29(2): 57-68.

Sperandeo, V. (1994). Principles of Professional Speculation, John Wiley \& Sons, Inc.

\section{A Figures}




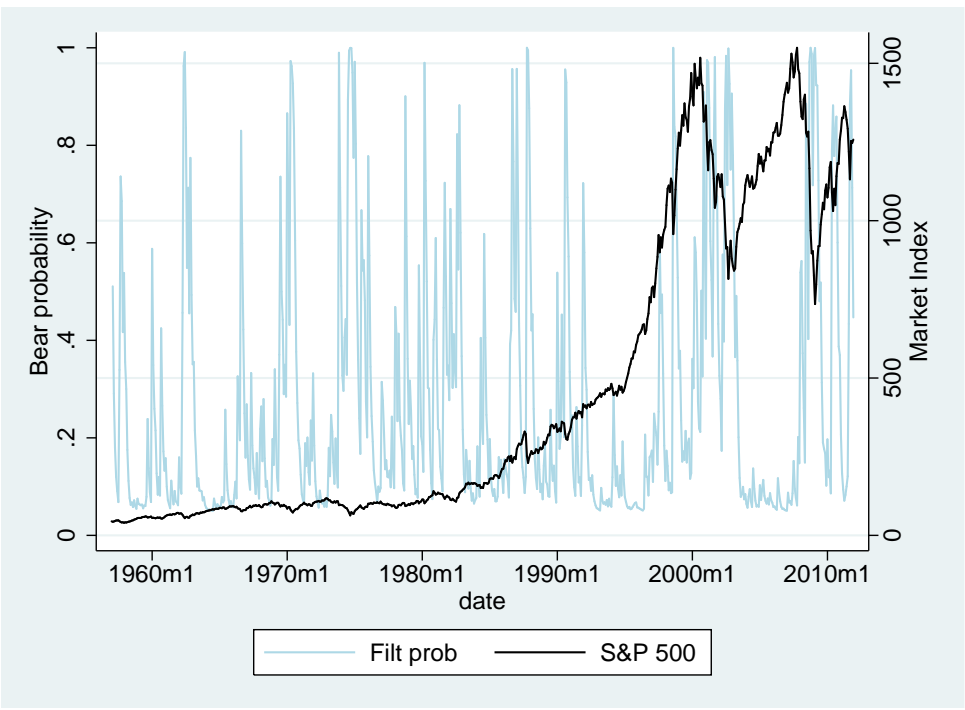

Figure 1: Filtered Probabilities for Bear Market from Markov Switching Model (right scale) AND S\&P 500 Index (LeFt SCALE) - SAMPLE PERIod 1957:M1-2011M12

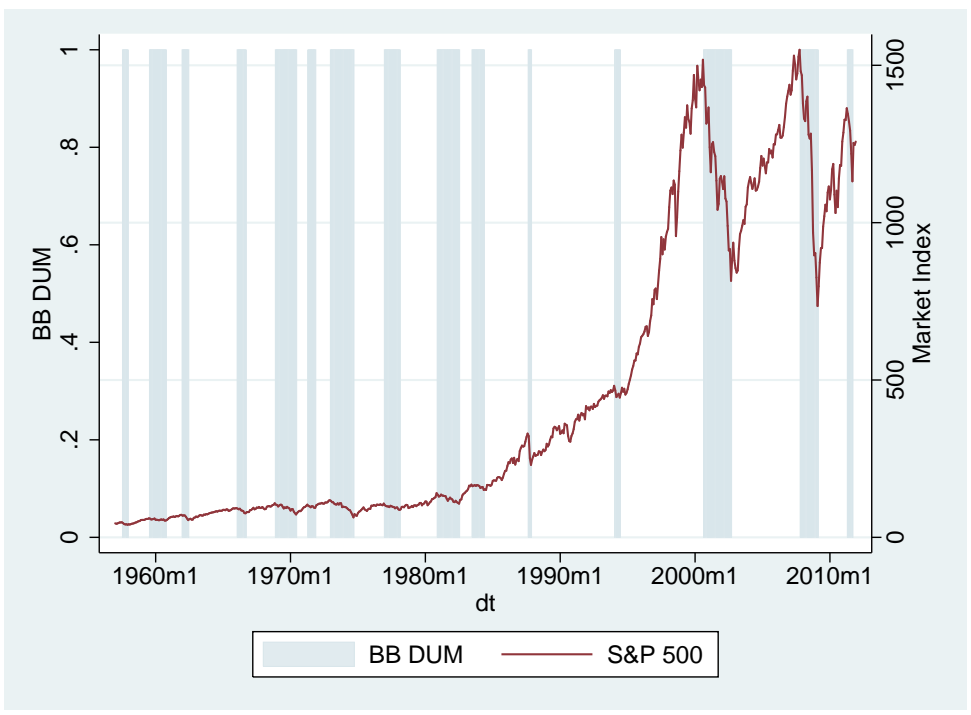

Figure 2: Bear Market Indicators as determined via Bry-Boschan Algorithm (left scale) and S\&P 500 IndeX (RIGHT SCALE) - SAMPle PERIOD 1957:M1-2011M12 

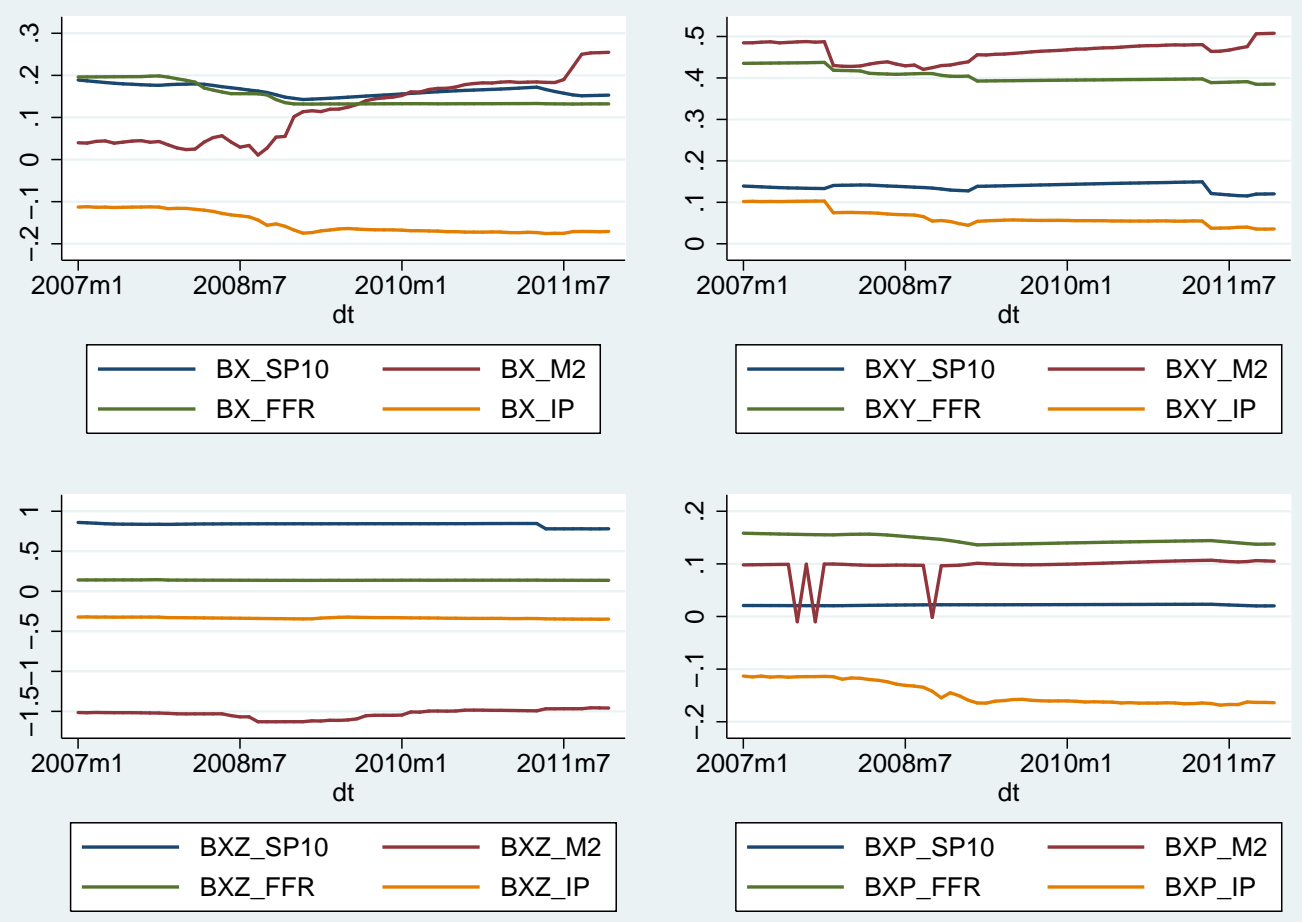

Figure 3: Recursive parameter estimates for 10-year Spread, Industrial Production, Broad Money (M2) And Fed Funds RATE FRom models X, XY, XZ AND XP - 2007M1 to 2011M12
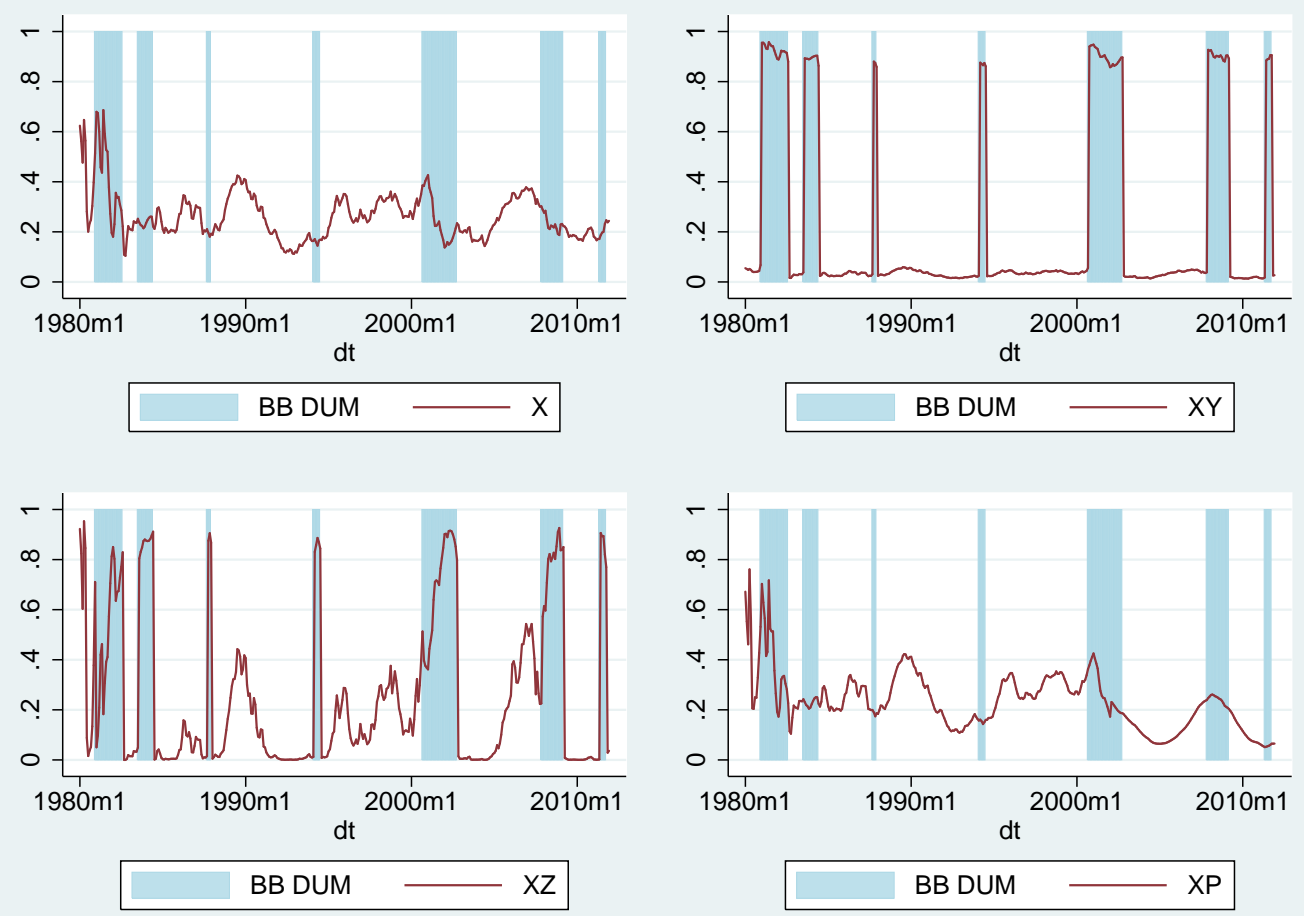

Figure 4: ONE-MONTh AHEAD PRobability (MARoon line) From PRobit MOdELS X, XY, XZ AND XP BASED ON 10 Y TERM SPREAD ALONGWith BEAR MARKET IndiCATORS AS DETERMINED VIA BRY-Boschan ALGORITHM (BARs) - ForeCAST PERIOd 1980:M1-2011M12 


\section{B Tables}

Table 1: Results From LineAR AND MARKOV-SWITCHING MODELS

Panel A: Linear ANd Markov-Switching Models

Linear model: $r_{t}=\mu+\varepsilon_{t}$

\begin{tabular}{rrr}
\hline$\mu$ & $\sigma$ & loglik \\
\hline 0.506 & 2.076 & -1898 \\
$(3.02)$ & $(24.28)$ &
\end{tabular}

\begin{tabular}{rrrrrrr}
\multicolumn{7}{c}{ Markov-switching model: $r_{t}=\mu_{s_{t}}+\sigma_{s_{t}} \varepsilon_{t}$} \\
\hline$\mu_{1}$ & $\mu_{0}$ & $\sigma_{1}$ & $\sigma_{0}$ & $p_{11}$ & $p_{00}$ & Loglik \\
\hline-0.989 & 1.064 & 6.183 & 3.175 & 0.845 & 0.942 & -1255 \\
$(-1.08)$ & $(5.06)$ & $(4.94)$ & $(6.07)$ & $(10.20)$ & $(36.98)$ &
\end{tabular}

Panel B: Predictive Regressions - In- And out-of- Sample Results

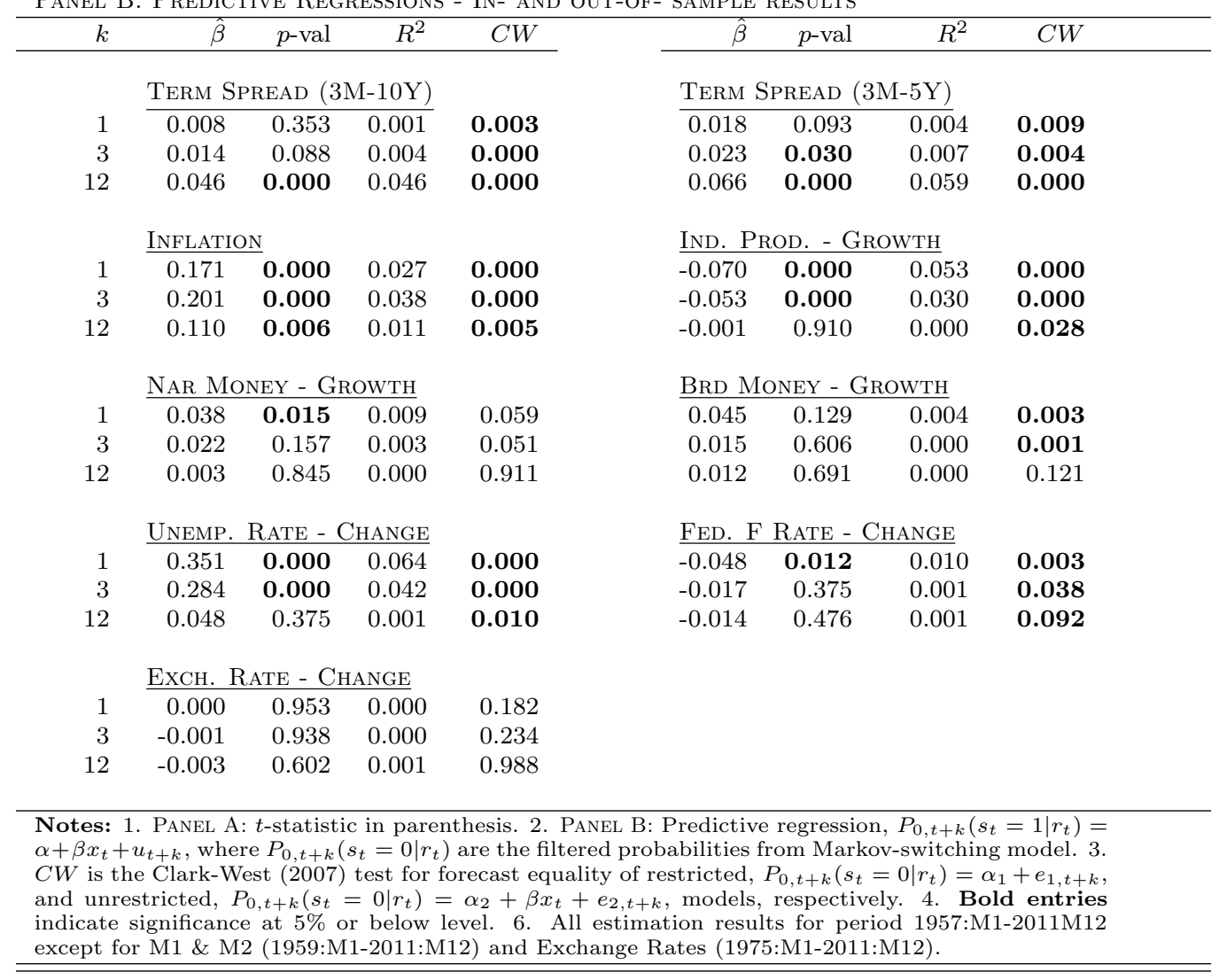


Table 2: Probit: In- And out-of-SAmple: Model $P_{t-k}\left(S_{t}=1\right)=\Phi\left(\alpha+\beta x_{t-k}\right)$

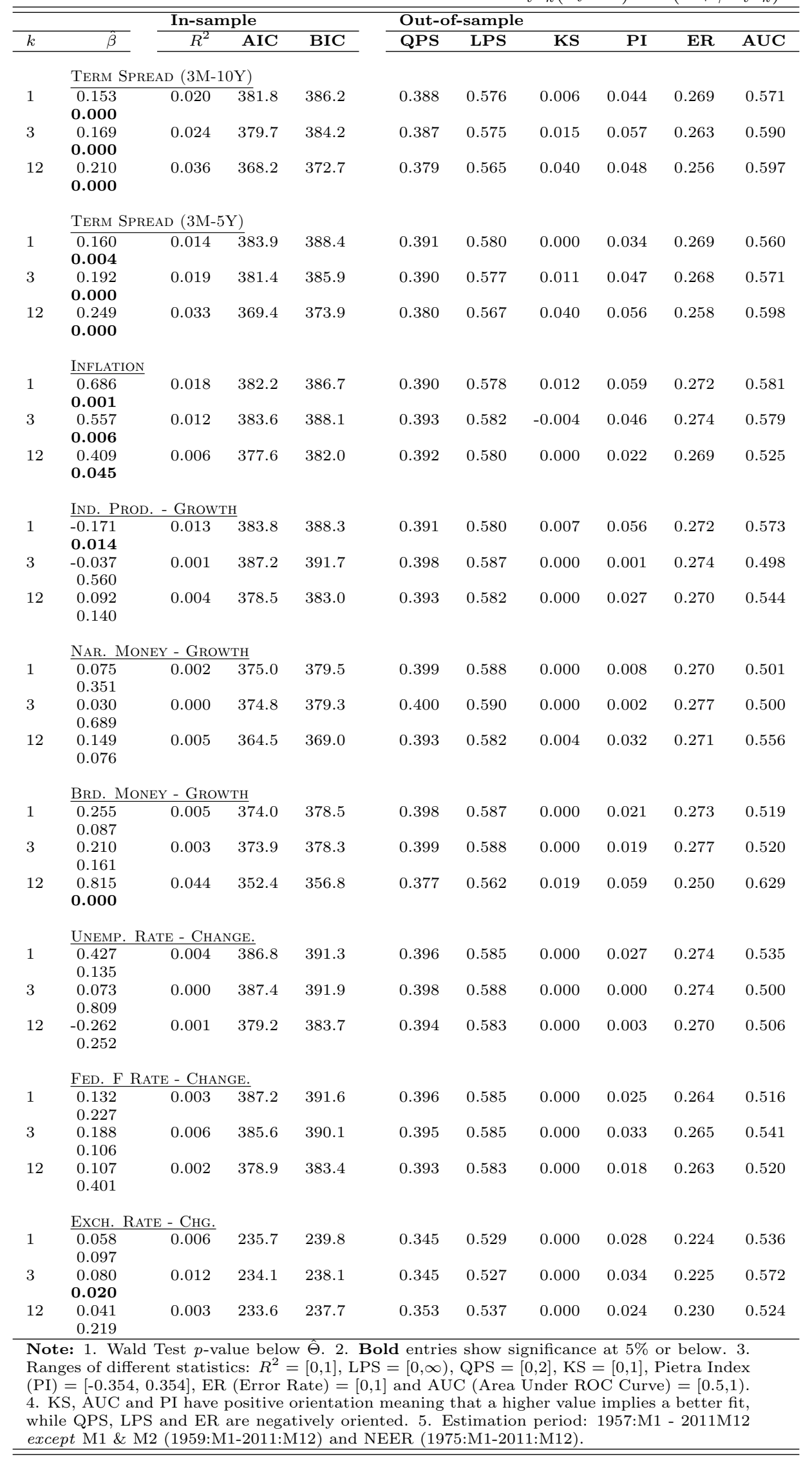


Table 3: Probit: In- And out-of-SAmple: Model $P_{t-k}\left(S_{t}=1\right)=\Phi\left(\alpha+\beta x_{t-k}+\delta S_{t-1}\right)$

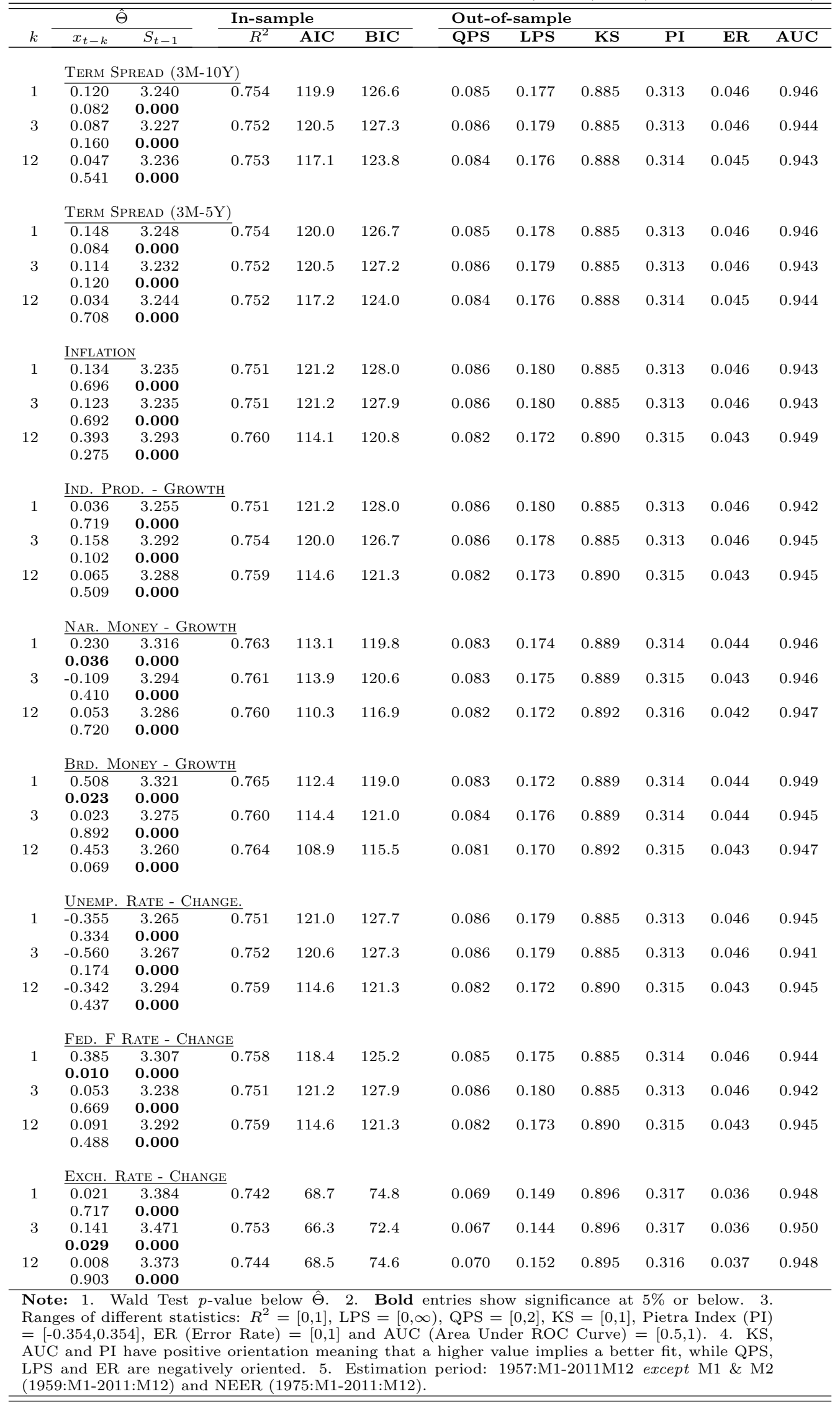


Table 4: Probit: In- And out-of-Sample: Model $P_{t-k}\left(S_{t}=1\right)=\Phi\left(\alpha+\beta x_{t-k}+\gamma \pi_{t-1}\right)$

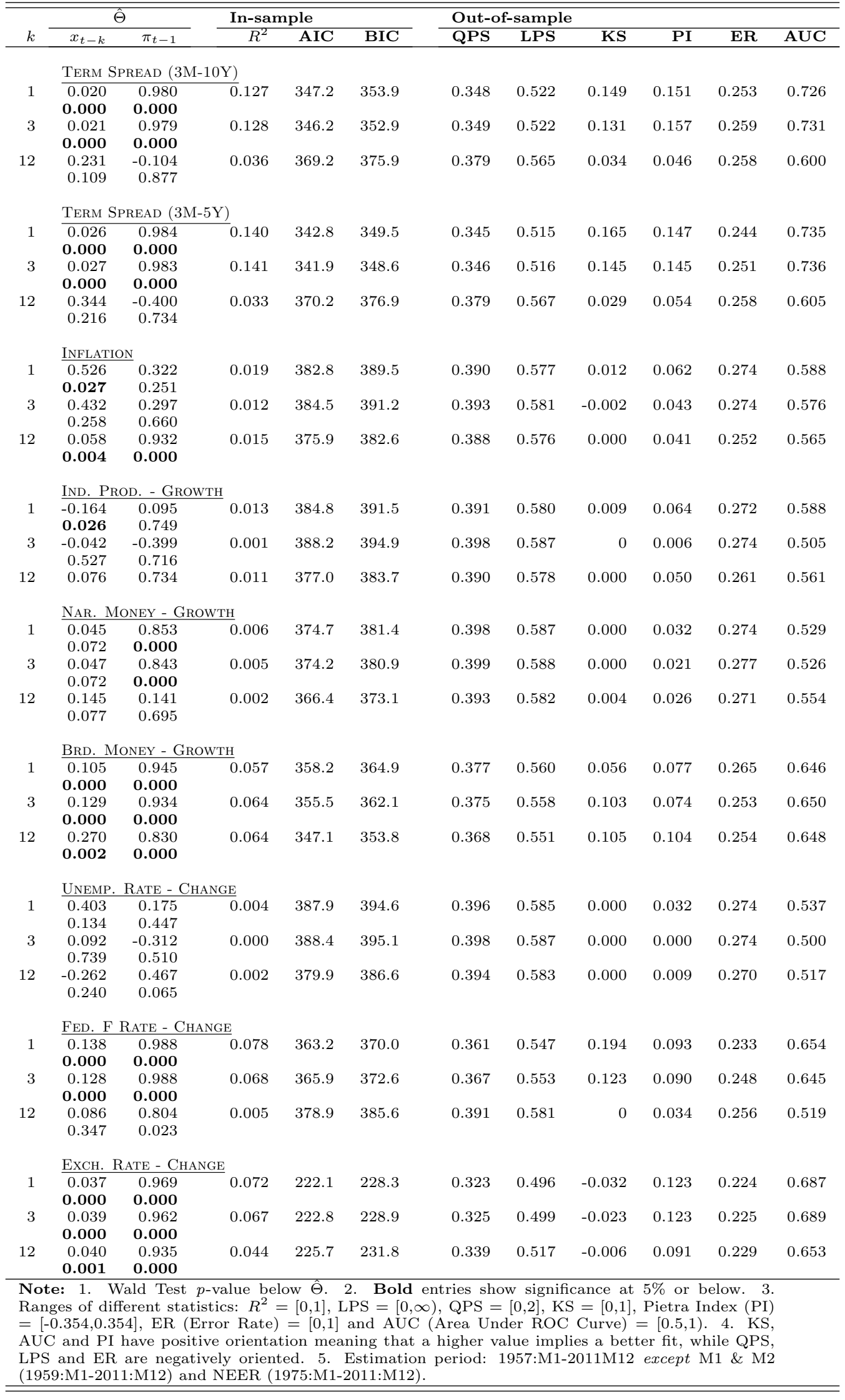


Table 5: Probit: In- And out-Of-SAmple: Model $P_{t-k}\left(S_{t}=1\right)=\Phi\left(\alpha+\beta x_{t-k}+\xi x_{t-1} . S_{t-1}\right)$

\begin{tabular}{|c|c|c|c|c|c|c|c|c|c|c|c|}
\hline \multirow[b]{2}{*}{$k$} & \multicolumn{2}{|r|}{$\hat{\Theta}$} & \multicolumn{3}{|c|}{ In-sample } & \multicolumn{6}{|c|}{ Out-of-sample } \\
\hline & $x_{t-k}$ & $x_{t-1} \cdot S_{t-1}$ & $R^{2}$ & AIC & BIC & QPS & LPS & $\mathbf{K S}$ & PI & ER & AUC \\
\hline \multirow{3}{*}{1} & TERM & READ (3M-10Y) & & & & & & & & & \\
\hline & 0.781 & -1.274 & 0.426 & 243.8 & 250.5 & 0.221 & 0.365 & 0.527 & 0.244 & 0.135 & 0.875 \\
\hline & 0.000 & 0.000 & & & & & & & & & \\
\hline \multirow[t]{2}{*}{3} & 0.584 & -1.049 & 0.374 & 261.9 & 268.6 & 0.232 & 0.394 & 0.530 & 0.232 & 0.140 & 0.873 \\
\hline & 0.000 & 0.000 & & & & & & & & & \\
\hline \multirow[t]{3}{*}{12} & 0.293 & -0.750 & 0.276 & 289.6 & 296.3 & 0.257 & 0.442 & 0.453 & 0.203 & 0.142 & 0.804 \\
\hline & 0.000 & 0.000 & & & & & & & & & \\
\hline & TERM $S$ & READ (3M-5Y) & & & & & & & & & \\
\hline \multirow[t]{2}{*}{1} & 0.966 & -1.609 & 0.444 & 237.1 & 243.8 & 0.211 & 0.355 & 0.603 & 0.248 & 0.123 & 0.875 \\
\hline & 0.000 & 0.000 & & & & & & & & & \\
\hline \multirow[t]{2}{*}{3} & 0.685 & -1.290 & 0.383 & 258.7 & 265.5 & 0.224 & 0.389 & 0.575 & 0.240 & 0.129 & 0.874 \\
\hline & 0.000 & 0.000 & & & & & & & & & \\
\hline \multirow[t]{3}{*}{12} & 0.325 & -0.956 & 0.291 & 284.4 & 291.1 & 0.243 & 0.434 & 0.472 & 0.237 & 0.117 & 0.817 \\
\hline & 0.000 & 0.000 & & & & & & & & & \\
\hline & INFLATI & & & & & & & & & & \\
\hline 1 & -2.806 & 7.203 & 0.538 & 203.0 & 209.7 & 0.156 & 0.304 & 0.726 & 0.275 & 0.079 & 0.894 \\
\hline & 0.001 & 0.000 & & & & & & & & & \\
\hline 3 & -1.041 & 6.094 & 0.485 & 222.1 & 228.8 & 0.174 & 0.334 & 0.638 & 0.276 & 0.076 & 0.898 \\
\hline & 0.006 & 0.000 & & & & & & & & & \\
\hline 12 & -0.504 & 5.755 & 0.474 & 220.8 & 227.5 & 0.173 & 0.337 & 0.659 & 0.276 & 0.073 & 0.892 \\
\hline & 0.111 & 0.000 & & & & & & & & & \\
\hline & IND. $\mathrm{Pl}$ & D. - GROWTH & & & & & & & & & \\
\hline 1 & -0.347 & 0.381 & 0.029 & 379.5 & 386.3 & 0.391 & 0.572 & -0.020 & 0.138 & 0.274 & 0.616 \\
\hline & 0.000 & 0.006 & & & & & & & & & \\
\hline 3 & -0.041 & 0.042 & 0.001 & 388.1 & 394.9 & 0.398 & 0.587 & 0 & 0.011 & 0.273 & 0.500 \\
\hline & 0.543 & 0.730 & & & & & & & & & \\
\hline 12 & 0.090 & 0.071 & 0.005 & 379.2 & 385.9 & 0.392 & 0.581 & 0.000 & 0.044 & 0.266 & 0.540 \\
\hline & 0.148 & 0.585 & & & & & & & & & \\
\hline & NAR. N & ONEY - GROWTH & & & & & & & & & \\
\hline 1 & -1.028 & 2.263 & 0.245 & 297.2 & 303.8 & 0.282 & 0.464 & 0.356 & 0.195 & 0.174 & 0.816 \\
\hline & 0.000 & 0.000 & & & & & & & & & \\
\hline 3 & 0.020 & 1.375 & 0.153 & 327.0 & 333.7 & 0.295 & 0.513 & 0.313 & 0.242 & 0.098 & 0.777 \\
\hline & 0.828 & 0.005 & & & & & & & & & \\
\hline 12 & 0.165 & 1.460 & 0.173 & 312.5 & 319.2 & 0.280 & 0.497 & 0.337 & 0.236 & 0.104 & 0.813 \\
\hline & 0.134 & 0.007 & & & & & & & & & \\
\hline & BRD. $\mathrm{N}$ & NEY - GROWTH & & & & & & & & & \\
\hline 1 & -1.458 & 5.265 & 0.623 & 166.2 & 172.92 & 0.132 & 0.257 & 0.745 & 0.293 & 0.065 & 0.927 \\
\hline & 0.000 & 0.000 & & & & & & & & & \\
\hline 3 & -0.280 & 4.984 & 0.579 & 182.3 & 188.9 & 0.145 & 0.284 & 0.692 & 0.299 & 0.055 & 0.914 \\
\hline & 0.175 & 0.000 & & & & & & & & & \\
\hline 12 & 0.252 & 4.903 & 0.590 & 172.8 & 179.5 & 0.139 & 0.273 & 0.698 & 0.301 & 0.055 & 0.923 \\
\hline & 0.209 & 0.000 & & & & & & & & & \\
\hline & UNEMP & Rate - Change & & & & & & & & & \\
\hline 1 & 0.073 & 0.822 & 0.007 & 386.7 & 393.5 & 0.392 & 0.583 & 0.000 & 0.081 & 0.216 & 0.480 \\
\hline & 0.356 & 0.161 & & & & & & & & & \\
\hline 3 & -0.069 & 0.918 & 0.007 & 386.1 & 392.8 & 0.392 & 0.584 & 0.000 & 0.112 & 0.192 & 0.524 \\
\hline & 0.969 & 0.265 & & & & & & & & & \\
\hline 12 & -0.269 & 0.770 & 0.006 & 378.6 & 385.3 & 0.390 & 0.581 & 0.000 & 0.086 & 0.219 & 0.540 \\
\hline & 0.282 & 0.194 & & & & & & & & & \\
\hline & FED. F & Rate - Change & & & & & & & & & \\
\hline 1 & 0.138 & -0.010 & 0.003 & 388.2 & 394.9 & 0.396 & 0.585 & 0.000 & 0.019 & 0.271 & 0.513 \\
\hline & 0.389 & 0.939 & & & & & & & & & \\
\hline 3 & 0.190 & 0.133 & 0.007 & 386.2 & 392.9 & 0.394 & 0.584 & 0.006 & 0.051 & 0.259 & 0.529 \\
\hline & 0.108 & 0.482 & & & & & & & & & \\
\hline 12 & 0.150 & 0.201 & 0.005 & 379.0 & 385.7 & 0.391 & 0.581 & 0.006 & 0.048 & 0.244 & 0.501 \\
\hline & 0.265 & 0.301 & & & & & & & & & \\
\hline & ECCH. & ATE - Change & & & & & & & & & \\
\hline 1 & 0.051 & 0.021 & 0.006 & 236.7 & 242.8 & 0.345 & 0.529 & 0.000 & 0.053 & 0.219 & 0.551 \\
\hline & 0.060 & 0.818 & & & & & & & & & \\
\hline 3 & 0.078 & 0.065 & 0.014 & 234.5 & 240.6 & 0.343 & 0.526 & 0.000 & 0.043 & 0.218 & 0.572 \\
\hline & 0.024 & 0.452 & & & & & & & & & \\
\hline 12 & 0.040 & 0.070 & 0.006 & 233.89 & 239.9 & 0.350 & 0.536 & 0 & 0.048 & 0.213 & 0.534 \\
\hline & 0.217 & 0.415 & & & & & & & & & \\
\hline & $\begin{array}{l}1 . \mathrm{W} \\
\text { atistics } \\
=[0,1 \\
\text { ing tha }\end{array}$ & $\begin{array}{l}\text { Test } p \text {-value } \\
R^{2}=[0,1], \text { LPs } \\
\text { and AUC (Are } \\
\text { a higher value }\end{array}$ & plies & $\begin{array}{l}\text { Bold } \\
\mathrm{PS}= \\
\mathrm{C} \text { Cur } \\
\text { etter fit }\end{array}$ & $=[0.5$ & IS & $\begin{array}{l}\mathrm{C} \text { an } \\
\mathrm{CR} \text { are }\end{array}$ & $\begin{array}{l}\text { below. } \\
=[-0.3 \\
\text { I have } \\
\text { gative }\end{array}$ & $\begin{array}{l}\text { Rang } \\
0.354] \\
\text { sitive } \\
\text { oriente }\end{array}$ & $\begin{array}{l}\text { of diffe } \\
R \text { (Err } \\
\text { ientati } \\
5 . \text { Es } \\
\text { 1:M12) }\end{array}$ & \\
\hline
\end{tabular}




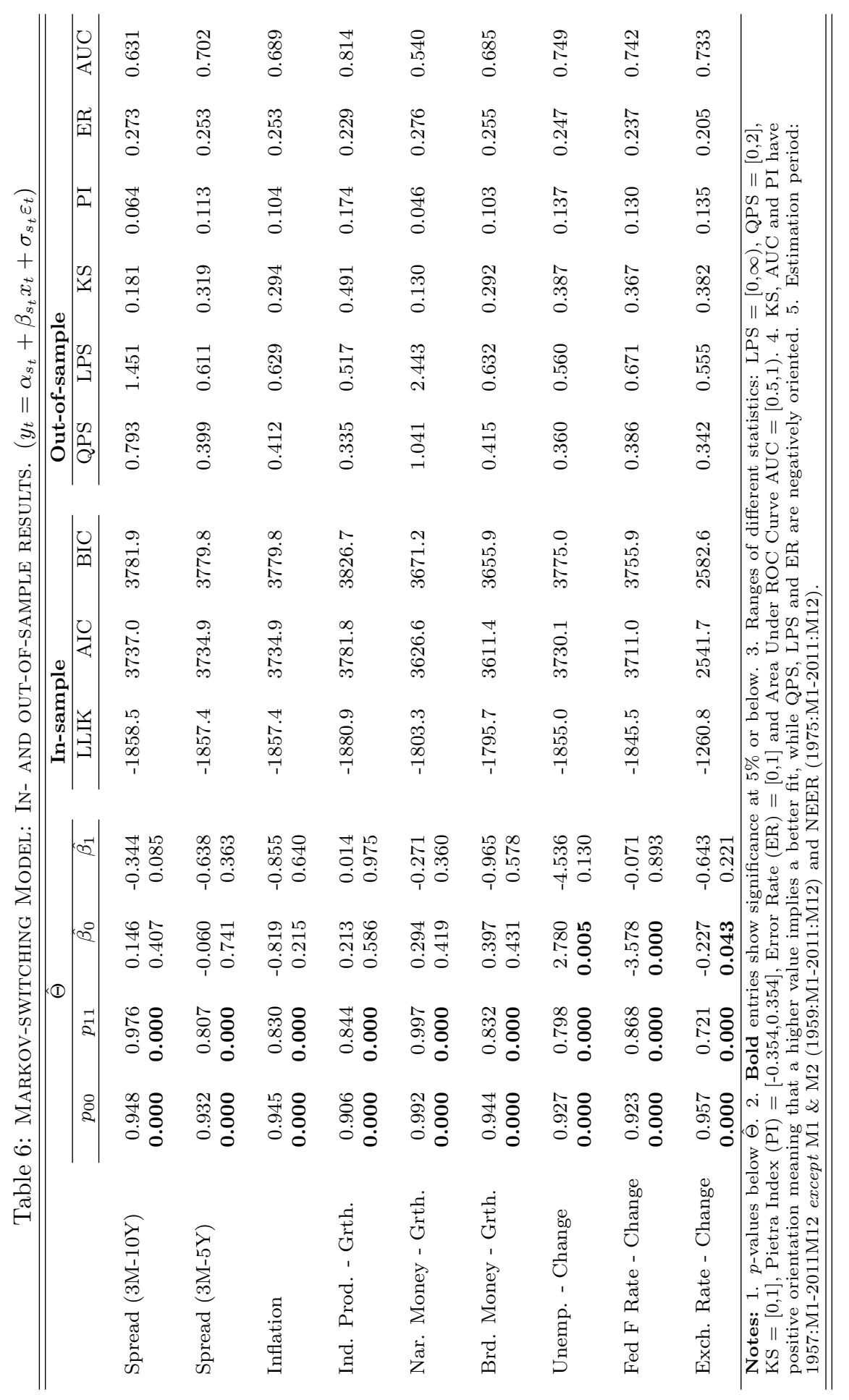




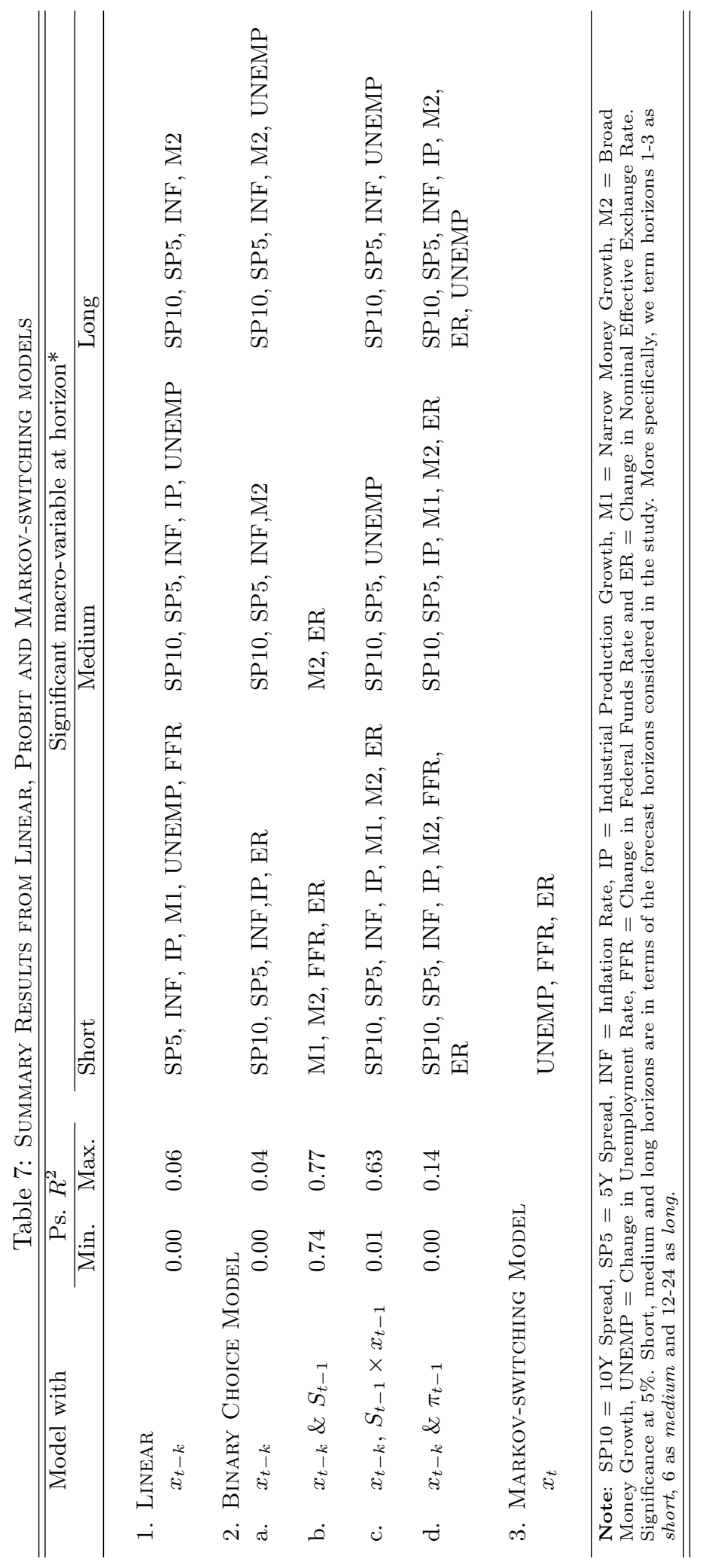


Table 8: Clark-West (2007) Test for equal MSPE - Probit \& Logit: Static (X) versus Dynamic Specifications

\begin{tabular}{|c|c|c|c|c|c|c|c|c|c|}
\hline & \multicolumn{9}{|c|}{ DYNAMIC SPECIFICATIONS } \\
\hline$k$ & $\mathbf{X Y}$ & $\mathbf{X Z}$ & $\mathbf{X P}$ & $\mathbf{X Y}$ & $\mathrm{XZ}$ & $\mathbf{X P}$ & $\mathbf{X Y}$ & $\mathbf{X Z}$ & $\mathbf{X P}$ \\
\hline \multicolumn{10}{|c|}{ Panel A: Probit } \\
\hline & \multicolumn{3}{|c|}{ Term Spread (3M-10Y) } & \multicolumn{3}{|c|}{ TERM SPREAd (3M-5Y) } & \multicolumn{3}{|c|}{ INFLATION } \\
\hline 1 & $\overline{0.000}$ & 0.000 & 0.000 & $\overline{0.000}$ & 0.000 & 0.000 & 0.000 & 0.000 & 0.253 \\
\hline 3 & 0.000 & 0.000 & 0.000 & 0.000 & 0.000 & 0.000 & 0.000 & 0.000 & 0.414 \\
\hline \multirow[t]{2}{*}{12} & 0.000 & 0.000 & 0.224 & 0.000 & 0.000 & 0.255 & 0.000 & 0.000 & 0.014 \\
\hline & \multicolumn{3}{|c|}{ IND. PROD. - GROWTH } & \multicolumn{3}{|c|}{ NAR. MONEY - GROWTH } & \multicolumn{3}{|c|}{ NAR. MONEY - GROWTH } \\
\hline 1 & 0.000 & 0.104 & 0.511 & 0.000 & 0.000 & 0.102 & 0.000 & 0.000 & 0.000 \\
\hline 3 & 0.000 & 0.321 & 0.417 & 0.000 & 0.000 & 0.055 & 0.000 & 0.000 & 0.000 \\
\hline \multirow[t]{2}{*}{12} & 0.000 & 0.195 & 0.010 & 0.000 & 0.000 & 0.386 & 0.000 & 0.000 & 0.000 \\
\hline & \multicolumn{3}{|c|}{ Unemp. Rate - Change } & \multicolumn{3}{|c|}{ Fed Funds Rate - ChG. } & \multicolumn{3}{|c|}{$\underline{\text { NEER Index - Change }}$} \\
\hline 1 & 0.000 & 0.004 & 0.390 & 0.000 & 0.819 & 0.000 & 0.000 & 0.051 & 0.000 \\
\hline 3 & 0.000 & 0.011 & 0.386 & 0.000 & 0.163 & 0.000 & 0.000 & 0.101 & 0.000 \\
\hline 12 & 0.000 & 0.029 & 0.221 & 0.000 & 0.116 & 0.105 & 0.000 & 0.111 & 0.000 \\
\hline \multicolumn{10}{|c|}{ Panel B: Logit } \\
\hline & \multicolumn{3}{|c|}{ Term Spread (3M-10Y) } & \multicolumn{3}{|c|}{ Term Spread (3M-5Y) } & \multicolumn{3}{|c|}{ INFLATION } \\
\hline 1 & $\overline{0.000}$ & 0.000 & 0.000 & $\overline{0.000}$ & 0.000 & 0.029 & 0.000 & 0.000 & 0.272 \\
\hline 3 & 0.000 & 0.000 & 0.000 & 0.000 & 0.000 & 0.000 & 0.000 & 0.000 & 0.440 \\
\hline 12 & 0.000 & 0.000 & 0.229 & 0.000 & 0.000 & 0.262 & 0.000 & 0.000 & 0.014 \\
\hline & \multicolumn{3}{|c|}{ Ind. PROD. - GROWTH } & \multicolumn{3}{|c|}{ NAR. MONEY - GROWTH } & \multicolumn{3}{|c|}{ BRD. Money - Growth } \\
\hline 1 & 0.000 & 0.162 & 0.542 & 0.000 & 0.000 & 0.119 & 0.000 & 0.000 & 0.000 \\
\hline 3 & 0.000 & 0.294 & 0.414 & 0.000 & 0.000 & 0.059 & 0.000 & 0.000 & 0.000 \\
\hline \multirow[t]{2}{*}{12} & 0.000 & 0.152 & 0.009 & 0.000 & 0.000 & 0.409 & 0.000 & 0.000 & 0.000 \\
\hline & \multicolumn{3}{|c|}{ UnemP. - Change } & \multicolumn{3}{|c|}{$\underline{\text { Fed. F Rate - Change }}$} & \multicolumn{3}{|c|}{ Exch. Rate - Change } \\
\hline 1 & 0.000 & 0.001 & 0.390 & 0.000 & 0.115 & 0.000 & 0.000 & 0.028 & 0.000 \\
\hline 3 & 0.000 & 0.004 & 0.386 & 0.000 & 0.129 & 0.000 & 0.000 & 0.060 & 0.000 \\
\hline 12 & 0.000 & 0.014 & 0.221 & 0.000 & 0.105 & 0.119 & 0.000 & 0.067 & 0.000 \\
\hline & & & r & & & $-k+$ & 3. $\mathbf{X}$ & $\begin{array}{c}\pi_{t}= \\
\text { qual M } \\
\text { bold en }\end{array}$ & \\
\hline
\end{tabular}


Table 9: Diebold-Mariano (1995) Test FOR EQUAlity of Forecasts

\begin{tabular}{|c|c|c|c|c|c|c|c|c|c|c|c|c|}
\hline & & Probit & vs Logit & & & Probit & MSReg & & & Logit v & MSReg & \\
\hline & $\mathrm{X}$ & $\mathrm{XY}$ & $\mathrm{XZ}$ & $\mathrm{XP}$ & $\mathrm{X}$ & $\mathrm{XY}$ & $\mathrm{XZ}$ & $\mathrm{XP}$ & $\mathrm{X}$ & $\mathrm{XY}$ & $\mathrm{XZ}$ & $\mathrm{XP}$ \\
\hline $\mathrm{TE}$ & M SPRE & $\mathrm{AD}(3 \mathrm{~N}$ & $-10 Y)$ & & & & & & & & & \\
\hline 1 & 0.071 & 0.909 & 0.001 & 0.426 & 0.000 & 0.000 & 0.000 & 0.000 & 0.000 & 0.000 & 0.000 & 0.000 \\
\hline 3 & 0.362 & 0.524 & 0.004 & 0.487 & 0.000 & 0.000 & 0.000 & 0.000 & 0.000 & 0.000 & 0.000 & 0.000 \\
\hline 12 & 0.443 & 0.741 & 0.005 & 0.445 & 0.000 & 0.000 & 0.000 & 0.000 & 0.000 & 0.000 & 0.000 & 0.000 \\
\hline $\mathrm{TE}$ & M SPRE & $\mathrm{AD}(3 \mathrm{~N}$ & $-5 Y)$ & & & & & & & & & \\
\hline 1 & 0.151 & 0.693 & 0.000 & 0.000 & 0.200 & 0.000 & 0.000 & 0.000 & 0.196 & 0.000 & 0.000 & 0.602 \\
\hline 3 & 0.460 & 0.508 & 0.000 & 0.400 & 0.009 & 0.000 & 0.000 & 0.000 & 0.009 & 0.000 & 0.000 & 0.000 \\
\hline 12 & 0.356 & 0.981 & 0.000 & 0.388 & 0.000 & 0.000 & 0.000 & 0.000 & 0.000 & 0.000 & 0.000 & 0.000 \\
\hline$\underline{\mathrm{INH}}$ & ATION & & & & & & & & & & & \\
\hline 1 & 0.966 & 0.972 & 0.000 & 0.519 & 0.027 & 0.000 & 0.000 & 0.025 & 0.027 & 0.000 & 0.000 & 0.025 \\
\hline 3 & 0.720 & 0.807 & 0.000 & 0.854 & 0.007 & 0.000 & 0.000 & 0.007 & 0.007 & 0.000 & 0.000 & 0.007 \\
\hline 12 & 0.710 & 0.980 & 0.001 & 0.583 & 0.002 & 0.000 & 0.000 & 0.002 & 0.002 & 0.000 & 0.000 & 0.002 \\
\hline INI & PROD & - GRO & $\mathrm{VTH}$ & & & & & & & & & \\
\hline 1 & 0.333 & 0.812 & 0.352 & 0.340 & 0.298 & 0.000 & 0.300 & 0.296 & 0.308 & 0.000 & 0.289 & 0.305 \\
\hline 3 & 0.799 & 0.490 & 0.625 & 0.760 & 0.011 & 0.000 & 0.011 & 0.011 & 0.011 & 0.000 & 0.011 & 0.011 \\
\hline 12 & 0.955 & 0.650 & 0.455 & 0.530 & 0.000 & 0.000 & 0.000 & 0.000 & 0.000 & 0.000 & 0.000 & 0.000 \\
\hline NA & MON & $\mathrm{Y}-\mathrm{GR}$ & OWTH & & & & & & & & & \\
\hline 1 & 0.460 & 0.559 & 0.000 & 0.598 & 0.000 & 0.000 & 0.000 & 0.000 & 0.000 & 0.000 & 0.000 & 0.000 \\
\hline 3 & 0.968 & 0.394 & 0.000 & 0.753 & 0.000 & 0.000 & 0.000 & 0.000 & 0.000 & 0.000 & 0.000 & 0.000 \\
\hline 12 & 0.593 & 0.591 & 0.000 & 0.911 & 0.000 & 0.000 & 0.000 & 0.000 & 0.000 & 0.000 & 0.000 & 0.000 \\
\hline$\underline{\mathrm{BR}}$ & . MON & $\mathrm{Y}-\mathrm{GR}$ & WTH & & & & & & & & & \\
\hline 1 & 0.460 & 0.658 & $\overline{0.000}$ & 0.824 & 0.054 & 0.000 & 0.000 & 0.004 & 0.054 & 0.000 & 0.000 & 0.005 \\
\hline 3 & 0.860 & 0.531 & 0.003 & 0.888 & 0.012 & 0.000 & 0.000 & 0.003 & 0.012 & 0.000 & 0.000 & 0.003 \\
\hline 12 & 0.707 & 0.585 & 0.042 & 0.917 & 0.001 & 0.000 & 0.000 & 0.000 & 0.001 & 0.000 & 0.000 & 0.000 \\
\hline UN & MP. R. & $\mathrm{TE}-\mathrm{Cl}$ & ANGE & & & & & & & & & \\
\hline 1 & 0.807 & 0.559 & 0.010 & 0.806 & 0.255 & 0.000 & 0.407 & 0.255 & 0.255 & 0.000 & 0.519 & 0.255 \\
\hline 3 & 0.930 & 0.849 & 0.055 & 1.000 & 0.121 & 0.000 & 0.063 & 0.121 & 0.121 & 0.000 & 0.049 & 0.121 \\
\hline 12 & 0.814 & 0.735 & 0.218 & 0.898 & 0.000 & 0.000 & 0.000 & 0.000 & 0.000 & 0.000 & 0.000 & 0.000 \\
\hline$\underline{\mathrm{FE}}$ & . FUnD & RATE - & CHANGF & & & & & & & & & \\
\hline 1 & 0.350 & 0.275 & 0.234 & 0.000 & 0.531 & 0.000 & 0.533 & 0.016 & 0.526 & 0.000 & 0.517 & 0.784 \\
\hline 3 & 0.393 & 0.773 & 0.281 & 0.450 & 0.017 & 0.000 & 0.016 & 0.001 & 0.016 & 0.000 & 0.016 & 0.001 \\
\hline 12 & 0.392 & 0.614 & 0.342 & 0.419 & 0.000 & 0.000 & 0.000 & 0.000 & 0.000 & 0.000 & 0.000 & 0.000 \\
\hline$\underline{\mathrm{Ex}}$ & H. RAT & $\mathrm{E}-\mathrm{CH}$ & NGE & & & & & & & & & \\
\hline 1 & 0.589 & 0.865 & 0.076 & 0.172 & 0.468 & 0.000 & 0.433 & 0.063 & 0.467 & 0.000 & 0.365 & 0.069 \\
\hline 3 & 0.504 & 0.139 & 0.202 & 0.513 & 0.358 & 0.000 & 0.294 & 0.165 & 0.359 & 0.000 & 0.261 & 0.175 \\
\hline 12 & 0.714 & 0.965 & 0.247 & 0.353 & 0.083 & 0.000 & 0.073 & 0.045 & 0.083 & 0.000 & 0.068 & 0.046 \\
\hline
\end{tabular}




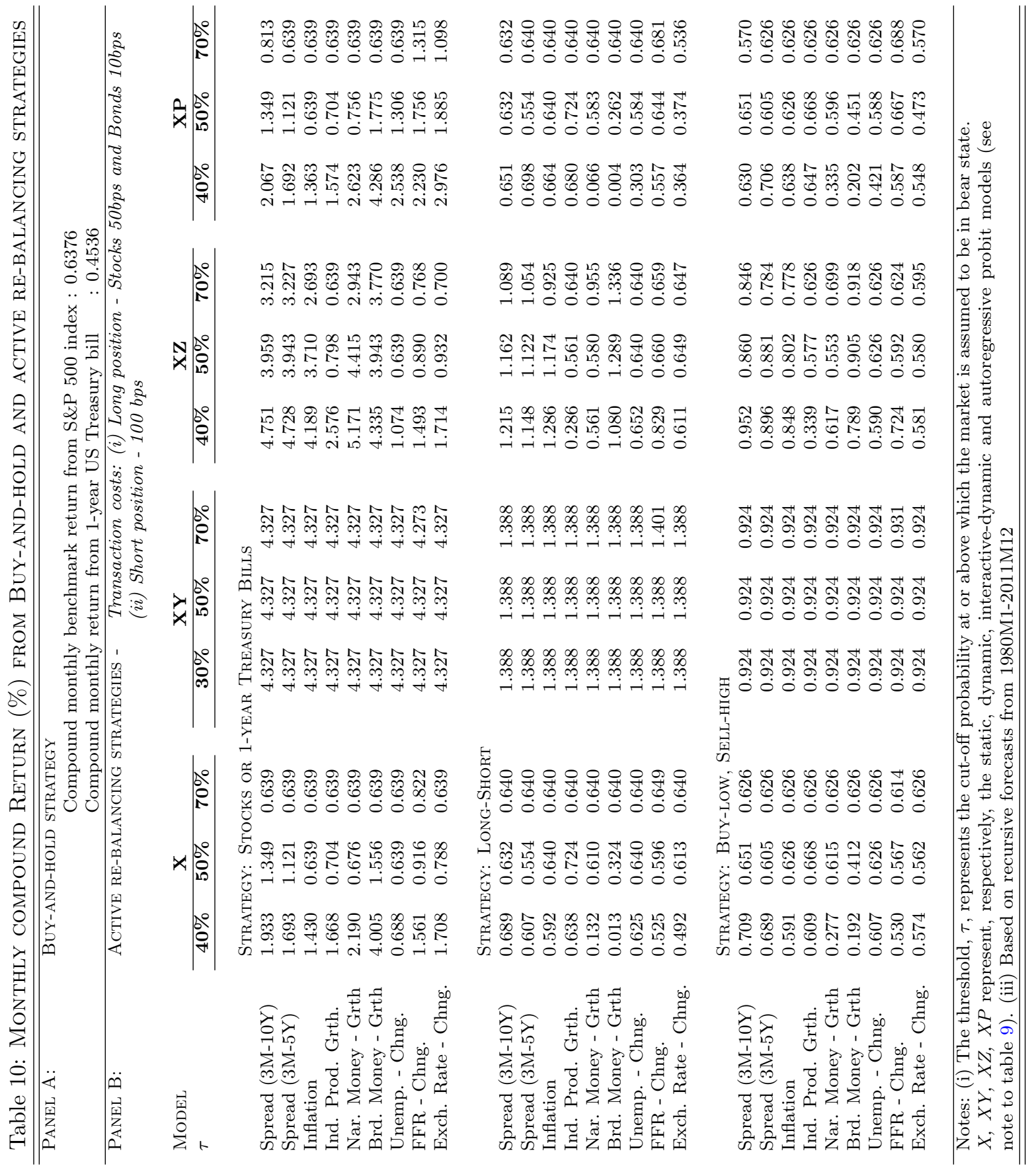

